\title{
Centennial- to millennial-scale hard rock erosion rates deduced from lumines- cence-depth profiles
}

Reza Sohbati

Jinfeng Liu

Mayank Jain

Andrew Murray

David Egholm

Richard Paris

Benny Guralnik

This is the accepted manuscript $\odot 2018$, Elsevier

Licensed under the Creative Commons AttributionNonCommercial-NoDerivatives 4.0 International

(CC BY-NC-ND 4.0)

http://creativecommons.org/licenses/by-nc-nd/4.0/

The published article is available from doi:

http://dx.doi.org/10.1016/j.epsl.2018.04.017 


\section{Centennial- to millennial-scale hard rock erosion rates deduced from}

\section{luminescence-depth profiles}

$7 \quad{ }^{a}$ Center for Nuclear Technologies, Technical University of Denmark, DK 4000 Roskilde, Denmark

$8{ }^{\mathrm{b}}$ The Nordic Laboratory for Luminescence Dating, Department of Geoscience, Aarhus University, DK 4000 Roskilde,

9 Denmark

$10{ }^{\mathrm{c}}$ State Key Laboratory of Earthquake Dynamics, Institute of Geology, China Earthquake Administration, China

$11{ }^{\mathrm{d}}$ Department of Geoscience, Aarhus University, 8000 Aarhus, Denmark

$12{ }^{\mathrm{e}}$ Department of Computing and Mathematics, University of Abertay, Dundee DD1 1HG, UK

13 Soil Geography and Landscape group and the Netherlands Centre for Luminescence Dating, Wageningen University, 14 Droevendaalsesteeg 3, 6708PB Wageningen, The Netherlands

*Corresponding author: $\underline{\text { liujf81@ies.ac.cn }}$

\section{Abstract}

The measurement of erosion and weathering rates in different geomorphic settings and over diverse temporal and spatial scales is fundamental to the quantification of rates and patterns of earth surface processes. A knowledge of the rates of these surface processes helps one to decipher their relative

21 contribution to landscape evolution - information that is crucial to understanding the interaction between climate, tectonics and landscape. Consequently, a wide range of techniques has been 
23 developed to determine short- $\left(<10^{2}\right.$ a) and long-term $\left(>10^{4}\right.$ a) erosion rates. However, no method is 24 available to quantify hard rock erosion rates at centennial to millennial timescales. Here we propose a novel technique, based on the solar bleaching of luminescence signals with depth into rock surfaces, to bridge this analytical gap. We apply our technique to glacial and landslide boulders in the Eastern Pamirs, China. The calculated erosion rates from the smooth varnished surfaces of 7 out of the 8 boulders sampled in this study vary between $<0.038 \pm 0.002$ and $1.72 \pm 0.04 \mathrm{~mm} \mathrm{ka}^{-1}$ (the eighth boulder gave an anomalously high erosion rate, possibly due to a recent chipping/cracking loss of surface).

Given this preferential sampling of smooth surfaces, assumed to arise from grain-by-grain surface loss, we consider these rates as minimum estimates of rock surface denudation rates in the Eastern Pamirs, 32 China.

\section{Introduction}

The erosion of the Earth's surface results from a combination of physical, chemical and biological weathering and the subsequent removal of weathering products by various transport agents. Erosion of rock surfaces may result from a range of processes such as dissolution, grain-by-grain attrition, chipping/frost cracking, and even massive bedrock landslides. Quantifying the rates and timing of such processes over various spatial and temporal scales is fundamental to determining the relative contribution of each process and thereby understanding landscape evolution. Bare hard rock surfaces are the most durable surficial features in the landscape and thus can have a long memory of the erosional history. Consequently, a wide range of methods have been developed to quantify erosion rates of subaerially-exposed rock surfaces (Turkowski and Cook, 2017). These include: i) the direct/indirect measurement of surface loss over laboratory timescales, or by comparison with resistant 
al., 2014), ii) the analysis of cosmogenic nuclides (CNs) produced within mineral grains from exposed

rock surfaces as a result of bombardment by secondary cosmic rays (Nishizumi et al., 1986; Lal, 1991), and iii) thermochronology using a wide range of radiogenic processes to determine the thermal history of rocks, and thus their exhumation rates (Braun et al., 2006). Depending on the length of the observation period or the age of the reference feature, the rates measured by the techniques in category (i) are integrated over sub-annual to multi-decadal timescales (Moses et al., 2014), while the rates derived using CNs and thermochronology are averaged over thousands to millions of years, respectively (Lal, 1991, Braun et al., 2006). The short (i.e. $<10^{2}$ years) and long (i.e. $>10^{4}$ years) timescales of these techniques leave an intermediate time interval of $10^{2}-10^{4}$ years over which there is currently no technique available for quantifying the erosion rates of rock surfaces. The centennial to millennial time intervals are of particular importance and interest to human society for evaluating the effects of climate change or anthropogenic activity on landscape evolution.

One of the major challenges in geomorphology is to make a link between different scales of observation (Schumm and Litchy, 1965; Warke and McKinley, 2011). Specifically, the timescale over which the rates of earth surface processes are averaged directly influences the apparent rates (e.g. Gardner et al., 1987; Viles, 2001; Koppes and Montgomery, 2009). Such measurement-interval bias can result in either underestimation (e.g. Kirchner et al., 2001) or overestimation (e.g. Lal et al., 2005) of short-term measurements compared to long-term average rates, hindering a linkage by simple extrapolation between the rates averaged over timescales that are orders of magnitude different (Gardner et al., 1987). It is clear that the development of a new analytical tool to bridge the gap between the decadal and millennial timescales would be of considerable value in erosion studies.

Several studies have shown that when a rock surface is first exposed to daylight, the latent luminescence, mainly from the constituent minerals quartz and feldspar, starts to decrease. The rate 
of this resetting (or 'bleaching') process decreases with depth as the incident light is attenuated (e.g.

69 Habermann et al., 2000; Laskaris and Liritzis, 2011). Based on this phenomenon, Sohbati et al. (2011,

70 2012a,b) proposed a new surface-exposure dating technique, which utilizes the time and depth 71 dependence of the residual latent luminescence. The longer the rock is exposed to daylight, the deeper 72 is the transition zone between the region of bleached latent luminescence at the surface and saturated 73 latent luminescence at depth. After calibration, the depth of this "optical bleaching front" can be 74 translated to an exposure time (Sohbati et al., 2011, 2012a,b).

$\mathrm{CN}$-depth profiles are influenced by the effect of erosion; Lal (1991) points out that the rock depth 76 equivalent to one absorption mean free path for cosmic rays is $\sim 50 \mathrm{~cm}$. In contrast, the corresponding absorption mean free path for light penetration into rocks is on the scale of millimetres (Sohbati et al., 2011, 2012a,b). Thus, luminescence-depth profiles are expected to be $\sim 2$ orders of magnitude more sensitive to the effect of erosion. In contrast to the effect of daylight exposure, the transition zone between the surface bleached latent luminescence and the saturated latent luminescence will become shallower, the higher the erosion rate. Nevertheless, this effect has been considered to be unimportant in all published applications, because the technique was applied to surfaces where archaeological evidence suggested negligible erosion (e.g. Pederson et al., 2014). However, the application of the technique to geological features, where constraints on surface preservation are rare on the centimetre scale (Lehmann et al., 2018 being an exception), necessitates the effect of erosion be taken into account (Sanderson et al., 2011). Here, we present a further development of the luminescence surface-exposure dating model (Sohbati et al., 2012b) that includes the effect of erosion on luminescence-depth profiles. We then use the new model to derive steady-state centennial- to millennial-scale hard-rock erosion rates from several surface-exposed glacial and landslide boulders from the Pamir plateau, China. 


\section{Theoretical framework}

The ubiquitous rock-forming minerals quartz and feldspar can store energy (in the form of trapped charge) through the absorption of ionizing radiation resulting from the decay of naturally-occurring radionuclides (mainly ${ }^{238} \mathrm{U}$ and ${ }^{232} \mathrm{Th}$ and their decay products, and ${ }^{40} \mathrm{~K}$ ) and cosmic rays. This trapped charge can be released during exposure to heat or light. Some of the energy released during the resetting is emitted as photons (i.e. as UV, visible, or near infrared luminescence); if the trapped charge is released by light (i.e. photon stimulation of trapped electrons), the luminescence emitted from the mineral is called optically stimulated luminescence (OSL; Aitken, 1998). OSL is now a wellestablished Quaternary dating method usually used to determine the time elapsed since mineral grains were last exposed to daylight (i.e. the burial age) (Aitken, 1998). Recently, luminescence has also been shown to be useful in surface exposure dating (Sohbati et al., 2012a, b).

\subsection{Luminescence surface exposure age}

In any rock sample that has been deeply buried and therefore shielded from light for an extended length of time (typically $>0.5 \mathrm{Ma}$ ) the trapped electron population in the constituent quartz and feldspar crystals will usually be in field saturation due to finite trapping capacity (e.g. Guralnik et al., 2013). If the rock is then exposed to daylight by an exhumation event (e.g. fracture, ice-scouring) the trapped electron population will begin to decrease. The electron detrapping rate decreases with depth as a result of the attenuation of incident light with depth, following Beer-Lambert law (e.g. Laskaris and Liritzis, 2011). The rate of change of trapped electron population at a particular depth is a result of competition between two effects: (i) the accumulation rate of trapped electrons due to ambient ionizing radiation, and (ii) the eviction rate of trapped electrons due to the daylight flux at a given depth. Thus, in a rock that has been exposed to daylight, the residual luminescence forms a sigmoidal profile that 
112 continues to evolve with time until it reaches secular equilibrium, when electron trapping and

113 detrapping rates are equal at all depths (Fig. 1a). For a given exposure time and daylight conditions, the

114 penetration depth and form of a luminescence profile depend on the opacity of the rock-forming

115 minerals and the relevant photoionization cross section(s). Assuming that luminescence signal is

116 proportional to the trapped electron population, Sohbati et al. (2011, 2012a, b) developed a

117 mathematical model describing the luminescence-depth profiles in rock surfaces and demonstrated its

118 application in surface exposure dating. According to this model, which assumes first-order kinetics for

119 electron trapping and detrapping, the instantaneous concentration of trapped electrons $n\left(\mathrm{~mm}^{-3}\right)$ at a

120 depth of $x(\mathrm{~mm})$ can be expressed as:

$\frac{d n}{d t}=(N-n) F(x)-n E(x)$

121 where $t(\mathrm{ka})$ is time, $N\left(\mathrm{~mm}^{-3}\right)$ is the concentration of electron traps, and $F(x)$ and $E(x)\left(\right.$ both $\left.\mathrm{ka}^{-1}\right)$ are

122 the rate constants describing electron trap filling and emptying, respectively.

$123 E(x)\left(\mathrm{ka}^{-1}\right)$ decreases with depth due to attenuation of daylight intensity into the rock following the

124 Beer-Lambert law:

$E(x)=\overline{\sigma \varphi_{0}} e^{-\mu x}$

125 where $\overline{\sigma \varphi_{0}}\left(\mathrm{ka}^{-1}\right)$ is the time-averaged detrapping rate constant at the surface of the rock and $\mu\left(\mathrm{mm}^{-1}\right)$

126 is the inverse of the mean free path of photons in the rock.

127 The coefficient $F(x)$ describes the trapping rate constant:

$128 \quad F(x)=\dot{D}(x) / D_{0}$

129 where $\dot{D}\left(\mathrm{~Gy} \mathrm{ka}^{-1}\right)$ is the natural dose rate and $D_{0}(\mathrm{~Gy})$ is the characteristic dose that fills $\sim 63 \%$ (i.e.

$1301-e^{-1}$ ) of the traps (Wintle and Murray, 2006). $D_{0}$ is an intrinsic property of the dosimeter and not

131 expected to have any systematic dependence on depth. $\dot{D}$ may have a weak dependence on depth into 
132 the rock, especially close to the surface (e.g. Sohbati et al., 2015) due to short range of the beta

133 particles, but this can be neglected for exposure dating, since near the surface, $E(x)$ exceeds $F(x)$ by

134 many orders of magnitude. Thus, in the present context, the dose rate may well be approximated as a

135 depth-independent constant, i.e. $F(x) \approx F=$ const.

136 When a previously shielded rock is first exposed to light, the initial trapped electron population

$137 n_{0} \cong N$, assuming a stable trapped electron population. Solving Eqn. (1) with the boundary condition

138 of $n=N$ at $t=0$ yields:

$\frac{n(x, t)}{N}=\frac{E(x) e^{-t[E(x)+F]}+F}{E(x)+F}$

139 According to this model, as the exposure time increases, the luminescence profile advances further 140 into the rock until $d n / d t \cong 0$ at all depths (Fig. 1a). In the absence of erosion (i.e. with a time141 invariant $x$ ), the model can be used to derive exposure ages as old as $100 \mathrm{ka}$, depending on the values 142 of the model parameters (Sohbati et al., 2012a, b) (Fig. 1a).

143 The millimetre depth scale of the luminescence resetting profiles, however, make them highly 144 susceptible to the effect of erosion (i.e. $x$ decreases with time). In any case, the assumption of zero 145 erosion is far from true for most terrestrial surfaces (e.g. Portenga and Bierman, 2011). Any exfoliation 146 of the rock surface and/or removal of bleached material from the surface due to weathering and erosion 147 moves the luminescence profile closer to the surface, preventing the derivation of a simple exposure 148 age. Below, we explore the effect of erosion on luminescence-depth profiles with the aim of deriving 149 erosion rates from such data. 


\subsection{Luminescence steady-state erosion rate}

151 The spatially-uniform removal of the uppermost material from a column of rock at a steady rate $\varepsilon$

$152\left(\mathrm{~mm} \mathrm{ka}^{-1}\right)$, affects the depth of all underlying material as follows:

$\frac{d x}{d t}=-\varepsilon$

153 where $\varepsilon \geq 0$. Eqn. (5) can be integrated with regard to time to yield $x(t)=x_{0}-\varepsilon t$, where $x_{0}$ is an

154 arbitrary depth datum. Substitution of a time-dependent depth $x(t)$ from Eqn. (5) into the electron 155 detrapping rate constant $E(x)$ (Eqn. 2) results in:

$E(x(t))=\overline{\sigma \varphi_{0}} e^{-\mu\left(x_{0}-\varepsilon t\right)}=\left(\overline{\sigma \varphi_{0}} e^{-\mu x_{0}}\right) e^{\mu \varepsilon t}=E_{0} e^{\mu \varepsilon t}$

156 where $E_{0}=\overline{\sigma \varphi_{0}} e^{-\mu x_{0}}$ is the trap emptying rate constant at $x_{0}$. The substitution of Eqn. (6) into Eqn.

157 (1) yields:

$\frac{d n}{d t}=(N-n) F-n E_{0} e^{\mu \varepsilon t}$

158 which is functionally identical to the description of a luminescence-thermochronometer (Guralnik et

159 al., 2013), except for the sign within the exponential. This subtle difference, i.e. the trap emptying rate

160 increases (rather than diminishes) with time, leads to a substantially different solution for $n$ (Appendix

161 A). To describe steady-state erosion, we define the datum depth to be infinitely deep (i.e. $x_{0}=\infty$ ) (Lal,

162 1991), and obtain an analytical solution for Eqn. (7):

$\frac{n(x, \varepsilon)}{N}=M\left(1,1+\frac{F}{\mu \varepsilon},-\frac{E(x)}{\mu \varepsilon}\right)$

163 where $M$ is the confluent hypergeometric function (Abramowitz and Stegun, 1964), readily available in

164 the majority of common computing software (Appendix A). Eqn. (8) describes the luminescence-depth

165 profile in a rock surface that has been continuously eroding at a rate $\varepsilon\left(\mathrm{mm} \mathrm{ka}^{-1}\right)$ (Fig. 1b). 
A luminescence-depth profile can be interpreted either in terms of an apparent exposure age (Eqn. 4) or an apparent steady-state erosion rate (Eqn. 8). As in $\mathrm{CN}$ dating, in the absence of other information one cannot choose between the two interpretations (Lal, 1991); an independent constraint on age or erosion rate is required to identify which model to select and so derive the true erosion rate or age, respectively. Provided that all other model parameters (i.e. $\dot{D}, D_{0}, \mu$, and $\overline{\sigma \varphi_{0}}$ ) are quantified, the exposure age $(t)$ or erosion rate $(\varepsilon)$ can be derived from an observed luminescence-depth profile via 172 fitting of Eqns. (4) or (8), respectively.

In practice, there is a limit to how well a profile can be distinguished from a profile in secular equilibrium. Any luminescence-depth profile can be characterized by the depth $x_{50 \%}$, at which the signal intensity drops to $50 \%$ of that in saturation (at depth). In a steady-state profile, this depth $x_{50 \%, S S}$ can be easily predicted from Eq. (4) (when $t \rightarrow \infty$ ). Here, we make a conservative assumption that a depth difference of at least one mean free path (i.e. $1 / \mu)$ is required to experimentally distinguish a transient profile from a predicted steady-state profile. This means the apparent exposure age or erosion rate of any profile whose $\left(x_{50 \%}>x_{50 \%, S S}-1 / \mu\right)$ should be considered as apparent minimum age or maximum erosion rate, respectively.

We now test both the luminescence surface exposure and erosion rate models by applying them to several glacial and landslide boulders in the Eastern Pamirs, China. The surface exposure ages of all these boulders have been previously established using ${ }^{10} \mathrm{Be}$ dating.

\section{Study area and sampling sites}

The Tashkurgan Valley stretches NNW for $\sim 100 \mathrm{~km}$ along the trace of the Karakoram and 186 Tashkurgan faults, marking the junction between the Karakoram, Pamir and Western Tibet (Fig. 2).

187 The valley floor contains many landslide and glacial erratic boulders whose chronology can provide 
188 valuable information about the driving mechanisms such as enhanced earthquake activity and climate 189 change (Owen et al., 2012; Yuan et al., 2013). As a result, the area has been subject to extensive 190 research in recent years, mostly based on $\mathrm{CN}$ surface exposure dating of boulders. Tens of glacial and 191 landslide boulders have been dated using ${ }^{10}$ Be by various workers (e.g. Seong et al., 2009a,b,c; Owen 192 et al., 2012; Yuan et al., 2013; Xu and Yi, 2014), providing an excellent independent-age control 193 dataset for our model verification.

194 At different locations along the valley, we visited three sites previously studied by others (Seong et 195 al., 2009a; Owen et al., 2012; Yuan et al., 2013) (Fig. 2). These locations were selected based on (i) 196 well-constrained chronology as shown by converging ${ }^{10} \mathrm{Be}$ ages obtained from several (> 6) boulders at 197 each site, and (ii) ages covering a wide range of 7 to $70 \mathrm{ka}$ (Fig. 2). We sampled the flat tops of large 198 boulders (> $2 \mathrm{~m}$ in diameter) close to the points previously sampled for $\mathrm{CN}$ dating, as well as the 199 exposed surfaces of a few smaller boulders ( $<1 \mathrm{~m}$ in diameter) close to the large boulders (Fig. 3). 200 These were most likely deposited at the same time as the large boulders, but they are usually dismissed 201 in CN studies, mainly because of concerns related to post-depositional reworking. Boulder surfaces 202 varied from being smooth, visually homogenous with various degrees of desert varnish to more 203 sporadic $\mathrm{cm}$-scale exfoliation (Figs. 3 and 4). Sub-mm- to $\mathrm{mm}$-scale weathering and grain loss was 204 evidenced by friable surfaces from which individual grains could be readily removed by light 205 mechanical abrasion (rubbing by hand). Samples were collected from surfaces with abundant desert 206 varnish, where we assume chipping is probably a less important surface removal mechanism. 


\section{Methods}

\subsection{Sampling and sample preparation}

Blocks of $\sim 4 \times 4 \times 7 \mathrm{~cm}^{3}$ were cut from the boulder surfaces using a petrol-driven cut-off saw equipped with a dry-cut diamond blade (Fig. 3). Blocks were immediately wrapped in aluminium foil and light-tight plastic bags to avoid any further exposure to daylight after collection. Under subdued red-orange light in the laboratory, cores $10 \mathrm{~mm}$ in diameter and up to $50 \mathrm{~mm}$ long were drilled into blocks using a water-cooled diamond core drill; these cores were then cut into $1.2 \mathrm{~mm}$ thick slices using a water-cooled low-speed saw equipped with a $0.3 \mathrm{~mm}$ thick diamond wafer blade, giving a net slice spacing of $1.5 \mathrm{~mm}$. The outermost slices were treated by $10 \% \mathrm{HF}$ for $40 \mathrm{~min}$. and $10 \% \mathrm{HCl}$ for 20 min. to remove any weathering products. No treatment was given to inner slices (Sohbati et al., 2011).

A subsample of $\sim 150 \mathrm{~g}$ was also prepared from each sample for dose rate measurement. These were pulverized, homogenized and then cast in wax to prevent radon loss and to provide a reproducible counting geometry. They were then stored for at least three weeks to allow ${ }^{222} \mathrm{Rn}$ to reach equilibrium with its parent ${ }^{226} \mathrm{Ra}$ before the measurement.

\subsection{Analytical facilities and measurements}

Although quartz OSL is usually the preferred signal in sediment dating, it is often not sufficiently sensitive when measured in primary rocks (e.g. Sohbati et al., 2011; Guralnik et al., 2015). Thus, we made use of infrared stimulated luminescence (IRSL) signal to measure the solid rock slices. The IRSL signal originates almost entirely from feldspar grains in rock slices (e.g. Baril and Huntley, 2003).

Luminescence measurements were carried out using a Risø TL/OSL reader (model DA-20) with infrared light stimulation $\left(870 \mathrm{~nm}, \sim 130 \mathrm{~mW} \mathrm{~cm} \mathrm{c}^{-2}\right.$ ) and photon detection through a Schott BG 39/Corning 7-59 blue filter combination ( 2 and $4 \mathrm{~mm}$, respectively). Beta irradiations used a calibrated 
${ }^{90} \mathrm{Sr} /{ }^{90} \mathrm{Y}$ source mounted on the reader delivering a dose rate of $\sim 0.08 \mathrm{~Gy} \mathrm{~s}{ }^{-1}$ to the rock slices. The 230 IRSL signal was measured using a conventional single-aliquot regenerative-dose (SAR) protocol. The 231 residual natural signal $\left(\mathrm{L}_{n}\right)$ and the subsequent response to a test dose $\left(\mathrm{T}_{\mathrm{n}}\right)$ from each slice were 232 measured using an IRSL signal at $50^{\circ} \mathrm{C}\left(\mathrm{IR}_{50}\right)$ for $100 \mathrm{~s}$ (Wallinga et al., 2000). A pause of $30 \mathrm{~s}$ was 233 inserted before the stimulation to make sure that all the grains within a slice reached the stimulation 234 temperature. The same thermal pretreatment of $250^{\circ} \mathrm{C}$ for $100 \mathrm{~s}$ was applied before the natural and test 235 dose measurements. Each cycle of the SAR protocol finished with an IR stimulation at $290^{\circ} \mathrm{C}$ for $100 \mathrm{~s}$ 236 to minimize recuperation (Wallinga et al., 2007).

The radionuclide concentrations $\left({ }^{238} \mathrm{U},{ }^{226} \mathrm{Ra},{ }^{232} \mathrm{Th}\right.$ and $\left.{ }^{40} \mathrm{~K}\right)$ were determined using high-resolution 238 gamma spectrometry by measurement on a high-purity germanium detector for at least $24 \mathrm{~h}$. Details of the gamma spectrometry calibration are given in Murray et al. (1987). To calculate the size-dependent internal beta dose rate from ${ }^{40} \mathrm{~K}$ in $\mathrm{K}$-rich feldspar grains, a grain size and composition analysis was carried out, using scanning electron microscopy (SEM), on several slices from each rock to determine the average size of the constituent K-rich feldspar grains (Table 1S). Using the simplifying assumption that the grains are spherical with this dimension as the diameter, the beta dose rate contributions from ${ }^{40} \mathrm{~K}$ and ${ }^{87} \mathrm{Rb}$ were then calculated assuming a potassium content of $12.5 \pm 0.5 \%$ (Huntley and Baril, 1997) and ${ }^{87} \mathrm{Rb}$ content of $400 \pm 100 \mathrm{ppm}$ (Huntley and Hancock, 2001). A small internal alpha contribution of $0.10 \pm 0.05 \mathrm{~Gy} \mathrm{ka}^{-1}$ from internal ${ }^{238} \mathrm{U}$ and ${ }^{232} \mathrm{Th}$ was also included in the dose rates, 247 derived from ${ }^{238} \mathrm{U}$ and ${ }^{232} \mathrm{Th}$ concentration measurements by Mejdahl (1987). The radionuclide concentrations were converted to dose rate data using the conversion factors from Guérin et al. (2011). The contribution from cosmic radiation to the dose rate was calculated following Prescott and Hutton 250 (1994), assuming an uncertainty of 5\%. The water content is negligible. Radionuclide concentrations and infinite-matrix beta and gamma dose rates are summarized in Table S1. 


\section{Results}

\subsection{Estimation of model parameters}

To derive the exposure age $(t)$ (Eqn. 4) or the erosion rate $(\varepsilon)$ (Eqn. 8) by fitting the corresponding equations to luminescence-depth profiles, the values of other parameters in the models must be derived independently. This can be done either by derivation from first principles or by fitting the models to an appropriate calibration sample (Sohbati et al., 2011, 2012a, b). We next discuss the evaluation of the individual parameters:

Dose rate $(\dot{D})$ : Ideally, in order for the beta and gamma dose rates derived from gamma spectrometry to be applicable to the IRSL-depth profiles, they need to be modified to account for the deviation from the infinite-matrix assumption around the rock surface-air interface. However, as mentioned before, this is not relevant to our problem. In practice, the average linear beta attenuation coefficient in granitic rocks with a typical density of $\sim 2.6$ g.cm ${ }^{-3}$ is $\sim 1.9 \mathrm{~mm}^{-1}$ (e.g. Sohbati et al., 2015). Hence the beta dose rate reaches $\sim 98 \%$ of the infinite matrix dose rate at a depth of $\sim 2 \mathrm{~mm}$ in our samples. Given that electron detrapping rate due to daylight bleaching at such depths (i.e. $<2 \mathrm{~mm}$ ) is much higher than electron trapping rate by dose rate, the effect of beta dose rate variation in the bleached part of the profile is negligible. The gradient of gamma dose rate with depth, on the other hand, is much less steep than that of beta (e.g. Aitken, 1985) and occurs over the entire length of the profiles measured here (i.e. $\sim 3.5 \mathrm{~cm}$ ). The gamma linear attenuation coefficient was calculated following Sohbati et al. (2015). The calculated coefficient is $\sim 0.02 \mathrm{~mm}^{-1}$, which results in an increase of gamma dose rate by a factor of $\sim 1.5$ from the surface to a depth of $\sim 3.5 \mathrm{~cm}$; however, on average, the gamma dose rate is only $\sim 30 \%$ of the total dose rate in our samples. Thus, there is only a weak variation of total dose rate with depth, which may be neglected for the benefit of simplification of the 
274 model. The variation of cosmic dose rate due to the attenuation of cosmic rays into rocks was also 275 calculated using the depth dependence model of Prescott and Hutton (1994). The resulting beta 276 (including contributions from internal ${ }^{40} \mathrm{~K}$ and ${ }^{87} \mathrm{Rb}$ ), gamma and cosmic dose rates were then summed 277 and averaged over the length of each luminescence-depth profile to give the mean effective total dose 278 rate in Eqns. (4) and (8) (Table 1).

279 Characteristic dose $\left(D_{0}\right)$ : To estimate the value of $D_{0}$ for each boulder, the dose-response curves of 280 the surface and the deepest slice from one of the luminescence-depth profiles for each sample, were 281 measured up to high doses (up to $\sim 1000 \mathrm{~Gy}$, i.e. close to saturation). The resulting dose-response 282 curves were then fitted with a single saturating exponential function to calculate the value of $D_{0}$. 283 Although the resulting $D_{0}$ values vary significantly from sample to sample, no systematic difference 284 with depth within individual samples is observed. We therefore take an average of the two $D_{0}$ values 285 for each sample as the most representative value to be used in Eqns. (4) and (11) for the whole profile 286 (Table 1). overall rate of charge detrapping $E(x)\left(\mathrm{ka}^{-1}\right)($ Eqn. 2) is a function of charge detrapping rate at the surface of the rock $\overline{\sigma \varphi_{0}}\left(\mathrm{ka}^{-1}\right)$ and the linear light attenuation coefficient $\mu\left(\mathrm{mm}^{-1}\right)$ into the rock. These site-specific and material-dependent parameters can, in principle, be determined independently from 291 first principles and/or by controlled field and laboratory measurements. However, earlier theoretically292 derived values of $\overline{\sigma \varphi_{0}}$ have been shown to be orders of magnitude different from the empirically293 derived values obtained by regression of the model to known-age calibration samples (Sohbati et al., $2942011 ; 2012 a$ ), and no attempt to measure $\mu$ in the laboratory has been reported. The alternative 295 empirical approach is to quantify these parameters by fitting the model to a non-eroding known-age 
calibration sample (Sohbati et al., 2012a). Such a surface was serendipitously created in one location by 297 earlier workers collecting CN samples during an earlier field campaign in 2010 (sampling date given 298 by Zhaode Yuan, personal communication) (Fig. 4). Fresh chisel marks on the surface of the boulder 299 provide evidence that the surface has not eroded significantly during the known exposure period ( 3 300 years). We sampled two profiles within a few centimeters of each other; one was taken from the natural 301 surface of the boulder, complete with varnish, and a second from the bottom of a > 2-cm deep chiseled 302 surface (Fig. 4). A simple qualitative assessment shows that the signal resetting in the profile from the 303 original surface with a ${ }^{10} \mathrm{Be}$ age of 15.7 ka penetrates further into the rock than that in the core from the $304>2-\mathrm{cm}$ deep chisel mark (Fig. 4). This is in line with the prediction of the model that luminescence is 305 shows that the piece removed in 2010 was almost certainly thick enough $(>2 \mathrm{~cm})$ to eliminate the part 307 of the profile that was bleached prior to $\mathrm{CN}$ sampling (i.e. $<2 \mathrm{~cm}$, Fig. 4 ). We can thus be confident 308 that the present-day shallow profile was saturated at the surface as a result of sampling three years ago 309 (satisfying the condition of $n=N$ at the beginning of the bleaching-irradiation process, $t=0$ ) and has not undergone any significant erosion during this period.

A visual inspection of the resetting fronts in the two profiles also reveals that they have similar curvature (Fig. 4; see also Fig. S1). According to the model, the gradient of luminescence-depth 313 profiles is controlled by the attenuation of light into the surface ( $\mu$ in Eqn. 2). Given the material314 dependent nature of this parameter and the similarity of the curvature of the two profiles, we assume 315 that they have the same light attenuation coefficient (Fig. 4).

316 We fit the two datasets simultaneously by sharing $\overline{\sigma \varphi_{0}}$ and $\mu$ between the profiles and replacing the 317 length of exposure time $t$ by three years in the model for the shallow profile. The 3-year old profile is 
318 our reference data for calibration; it allows us to determine the values of the model parameters, and 319 thereby, the apparent exposure time for the deeper profile (Figs. 4 and 5c). The best-fit values for $\overline{\sigma \varphi_{0}}$ 320 and $\mu$ are $2165 \pm 51 \mathrm{ka}^{-1}$ and $0.59 \pm 0.01 \mathrm{~mm}^{-1}$, respectively. The apparent best-fit luminescence surface-

321 exposure age for the deeper profile is $2.5 \pm 0.3 \mathrm{ka}$, much younger than the ${ }^{10} \mathrm{Be}$ exposure age of $15.7 \mathrm{ka}$ 322 obtained from the same surface. This obvious age underestimation is presumed to arise from the effect 323 of erosion on the luminescence-depth profile. Using the best-fit values for $\overline{\sigma \varphi_{0}}$ and $\mu$ and setting the 324 exposure time $t$ to 15.7 ka results in a predicted luminescence profile that penetrates much deeper than 325 that measured (Figs. 4 and 5c). This is the profile that would have developed in $15.7 \mathrm{ka}$, had there been 326 no erosion. Similarly, we can model the secular-equilibrium profile $(d n / d t=0)$ for zero erosion rate 327 (Figs. 4 and 5c); it penetrates even deeper than the 15.7 ka profile. All three profiles are statistically 328 distinguishable suggesting that in the absence of erosion a $15.7 \mathrm{ka}$ profile could have been resolved 329 from the secular-equilibrium profile.

\subsection{The effect of feldspar IRSL signal instability on the models}

Our models implicitly assume that the competition between electron trap filling by environmental radiation and trap emptying by optical bleaching in IRSL-depth profiles is governed by first-order kinetics. However, trapped electrons participating in IRSL often undergo localized recombination from the ground state and/or the excited state of the trap leading to signal instability (e.g., Huntley, 2006; Jain et al., 2015). Such a signal instability is expected to affect the shape of the luminescence-depth profile because recently-trapped charge (i.e. charge population far from field equilibrium; Lamothe et al., 2003) makes up a larger fraction of the total at low signal intensities (i.e. shallower depths) than at high signal intensities closer to saturation (i.e. deeper in the profile). Nonetheless, for our samples we 
ages (discussed below) are, with one exception, $<12 \mathrm{ka}$. On such timescales, any second order effects related to instability of the signal acquired due to ambient ionizing radiation is negligible compared to 342 bleaching by daylight close to the surface.

To test the validity of this approximation, we have superimposed the bleaching profiles from the 3344 year old calibration sample (Fig. 4, profile 1) with the profile from the adjacent natural surface 345 presumed to have been exposed for $15.7 \mathrm{ka}\left({ }^{10} \mathrm{Be}\right.$ age; Fig. 4, profile 2), by simply adding $12 \mathrm{~mm}$ to the 346 depth scale of the 3-year old profile (see Fig. S1). The two profiles are now indistinguishable, 347 confirming that any effect of signal instability on the shape of the profile is negligible over a timescale the characteristic sigmoidal shape as predicted by the model for constantly exposed surfaces; they start

\subsection{Apparent ages and erosion rates}

As presented earlier, we have two explicit models represented by two different analytical solutions: the age model (Eqn. 4; assumes no erosion and solves for exposure age) and the steady-state erosion rate model (Eqn. 8, assumes no age information and solves for erosion rate). In this section, we first apply the age model to all the luminescence-depth profiles and then the erosion rate model.

Figure 5 shows the IRSL-depth profiles measured into the 8 boulder surfaces. All the profiles have at negligible values at the surface and gently rise to saturation at depths $>20 \mathrm{~mm}$. Given that all the samples were collected from the top flat surfaces of boulders from localities that are $<100 \mathrm{~km}$ apart within the valley, we assume that they have all been exposed to similar solar insolation $\left(\varphi_{0}\right)$. Also, it has been shown that feldspars of different compositions have similar bleaching response (Spooner, 1994) and so similar optical cross sections $(\sigma)$. Thus, one can assume that all our samples have the same value of $\overline{\sigma \varphi_{0}}$ as determined above from the calibration sample. On the other hand, $\mu$ is a sample- 
362 dependent parameter that can vary from one rock to another. Accordingly, we simultaneously fit Eqn. 4 363 to all the profiles, sharing $\overline{\sigma \varphi_{0}}\left(2165 \pm 51 \mathrm{ka}^{-1}\right.$, derived from the calibration sample) between all the fits, 364 but leaving $\mu$ a free parameter.

365 Figure 5 shows the resulting best fits and the apparent luminescence surface-exposure ages for all 366 the boulders. The corresponding values of $\mu$ are summarized in Table 1. The apparent luminescence 367 age of sample MUST10-1 is $11.6 \pm 2.3$ ka which is comparable with the ${ }^{10} \mathrm{Be}$ age of $9.9 \pm 0.9$ ka obtained 368 from the same surface (Fig. 5a). Also, boulder XJ64-1 has a minimum age of 36.4 \pm 2.1 ka constrained 369 by our $1 / \mu(\mathrm{mm})$ limit on the penetration depth of the $x_{50 \%}$; this minimum age is consistent with the $370{ }^{10} \mathrm{Be}$ age of $86.4 \pm 8.3 \mathrm{ka}$ for this boulder (Fig. $5 \mathrm{~h}$ ). For all the other samples however, the apparent 371 luminescence surface exposure ages are significantly younger than the corresponding ${ }^{10} \mathrm{Be}$ ages. This 372 systematic underestimation in apparent luminescence exposure ages suggests that the profiles in these 373 boulders are either in secular equilibrium or have been affected by erosion. To investigate this, a 374 similar approach as was used with the calibration sample was adopted; we assume no erosion, and 375 model two profiles for each sample by setting the exposure time to the ${ }^{10} \mathrm{Be}$ age of the sample or to 376 infinity (Fig. 5).

377 As mentioned above, the apparent luminescence exposure age of sample MUST10-1 is comparable 378 to its ${ }^{10} \mathrm{Be}$ age. As a result, the predicted profile corresponding to the ${ }^{10} \mathrm{Be}$ age in sample MUST10-1 is 379 indistinguishable from the best fit of the model to the data, whereas the predicted secular-equilibrium 380 profile is discernibly deeper (Fig. 5a). Also, in case of XJ64-1, the predicted steady-state and the fitted 381 age model profiles are identical and deeper than the predicted ${ }^{10} \mathrm{Be}$ profile, indicating that this sample 382 must be in secular equilibrium (Fig. 5h). Except for MUST10-1 and XJ64-1, the predicted ${ }^{10} \mathrm{Be}-$ 383 equivalent and steady-state resetting profiles in all the other boulders penetrate to greater depths than 
384 the observed profiles, suggesting that the measured profiles are distinct and far from secular 385 equilibrium; they must therefore have been affected by erosion (Fig. 5).

386 Given that erosion has most likely played a significant role in the development of the IRSL-depth 387 profiles, we now test whether our data can be explained by the erosion rate model (Eqn. 8). As with 388 Eqn. 4, we simultaneously fit Eqn. 8 to all the profiles, sharing $\overline{\sigma \varphi_{0}}\left(2165 \pm 51 \mathrm{ka}^{-1}\right.$, derived from the 389 calibration sample) between all the fits, but leaving $\mu$ a free parameter. Figure 5 shows that the model 390 provides excellent fits to the data from all the samples; the fits are indistinguishable from and so 391 superimpose those obtained using the age model (i.e. without erosion; Fig. 5). The resulting values of $\mu$ 392 are summarized in Table 1. These are also indistinguishable from those derived using Eqn. 4 (Table 1); 393 this is not surprising since $\mu$ is a material-dependent parameter and should not be dependent on age or 394 erosion rate (see also Fig. S2 and associated text). The apparent erosion rates derived from Eqn. 8 vary 395 from $<0.038 \pm 0.002 \mathrm{~mm} \mathrm{ka}^{-1}$ for sample XJ64-1 to $444 \pm 12 \mathrm{~mm} \mathrm{ka}^{-1}$ for sample XJ64 (Table 1).

\section{Discussion}

The apparent luminescence surface-exposure age of sample MUST10-1 is 11.6 \pm 2.3 ka which, within error limits, is in agreement with the ${ }^{10} \mathrm{Be}$ age of $9.9 \pm 0.9 \mathrm{ka}$ obtained from the same surface (Fig. 5a). This is the first time that a luminescence surface exposure age has been verified using independent age control. Given that luminescence-depth profiles are much more susceptible to the effect of erosion than $\mathrm{CN}$-depth profiles, the agreement between the two ages implies a low rate of erosion for the surface of this boulder. The application of the erosion rate model indeed confirms this implication, as it yields an apparent luminescence erosion rate of $0.09 \pm 0.02 \mathrm{~mm} \mathrm{ka}^{-1}$ (Fig. 5a).

Boulder XJ64-1 with a ${ }^{10} \mathrm{Be}$ age of $86.4 \pm 8.3 \mathrm{ka}$ has a minimum luminescence age of $36.4 \pm 2.1 \mathrm{ka}$ 405 (Fig. 5h). The fact that the observed profile is consistent with the expected profile in secular 
equilibrium assuming no erosion, suggests a negligible erosion of the surface of XJ64-1 (Fig. 5h). This suggestion is further confirmed by the application of erosion rate model, which results in a maximum apparent erosion rate of $0.038 \pm 0.002 \mathrm{~mm} \mathrm{ka}^{-1}$ (Fig. 5h). The surface of boulder XJ64-1 currently lies only a few centimetres above the ground (Fig. 3h) and thus any effect of wind abrasion at its surface must be limited (Shao, 2009). The abundant desert varnish on the surface of this boulder (Fig. 3h) also argues for an absence of significant erosion, indicating that within the geological context, the very low erosion rate obtained here is plausible. Nevertheless, given the size and position of the boulder in the landscape, we cannot completely rule out occasional burial deep enough to shield it from daylight, but not from the cosmic rays. In such a scenario, the effective value of $\overline{\sigma \varphi_{0}}$ would be smaller than that for the calibration sample. However, any decrease in the effective $\overline{\sigma \varphi_{0}}$ value would only bring the equilibrium profile to depths shallower than we observe. Based on our fitting results we can conclude that the cover could have never been more than $\sim 46 \%$ (minimum luminescence age $/{ }^{10} \mathrm{Be}$ age) of the total time since the emplacement of the boulder.

In contrast to XJ64-1, the nearby large boulder (XJ64) has an anomalously high apparent erosion rate of $444 \pm 12 \mathrm{~mm} \mathrm{ka}^{-1}$ (Fig. $5 \mathrm{~g}$ ), which is several orders of magnitude larger than those obtained for the other boulders in this study. The surface of XJ64 has visibly undergone considerable erosion compared to the other boulders, as evidenced by its rough, unvarnished surface (see also Fig. 3). Nevertheless, steady-state erosion at such a high rate seems very unlikely in an environment where it is expected that wind abrasion dominates (Portenga and Bierman, 2011). In addition, the boulder has been exposed for $\sim 70 \mathrm{ka}$, and this would imply a loss of $>3 \mathrm{~m}$, making the $\mathrm{CN}$ age a serious underestimate and the total loss even greater. A more likely explanation is that the observed profile was inadvertently 
428 We also note that the value of $\mu$ for this boulder $\left(0.2 \mathrm{~mm}^{-1}\right)$ is $\sim 3$ times smaller than any of the values 429 obtained for the other boulders, and this may reflect some undetected failure of the application of the 430 model to this sample.

431 Finally, the observed marked variability in surface loss, as evidenced by apparent surface roughness 432 in the field (Fig. 3), implies that the luminescence erosion rates derived here from such smooth 433 varnished spots must be regarded as minimum estimates of rock surface erosion rates in the Eastern 434 Pamirs, China. The observation of a significant varnish patina on surfaces probably eroding at $>0.1$ to $4352 \mathrm{~mm} \mathrm{ka}^{-1}$ suggests that the varnish accumulation rates at the Eastern Pamirs must be higher than the 436 fastest rates of $\sim 600 \mu \mathrm{m} \mathrm{ka}^{-1}$ previously documented in southwestern United States (Spilde et al., 437 2013).

\subsection{Luminescence-depth profile: chronometer or erosion-meter?}

In order to discuss the information available in a luminescence-depth profile, we first simulate the behavior of the erosion rate model (Eqn. 8) for erosion rates of 0 and $1.5 \mathrm{~mm} \mathrm{ka}^{-1}$. The model profiles are first generated by setting $t$ in Eqn. 4 to a known age (i.e. from 0.1 a to $100 \mathrm{ka}$ ) and then fitted by

442 Eqn. (8) using the appropriate erosion rate. The other model parameters (i.e. $\dot{D}, D_{o}, \overline{\sigma \varphi_{0}}$ and $\mu$ ) are 443 assigned values comparable to those obtained for our samples. Figure 6a plots, against exposure time, 444 the product of the $x_{50 \%}$ of the resulting model profiles and $\mu$; this gives a material independent, 445 dimensionless parameter which quantifies the depth, in multiples of the mean free path, at which 446 luminescence reaches $50 \%$ of its saturation value. We define the extrapolation of the horizontal 447 (steady-state) part of the $1.5 \mathrm{~mm} \mathrm{ka}^{-1}$ curve to the zero erosion rate curve to be the equilibrium age limit 448 (i.e. $\sim 1 \mathrm{ka}$ ) recorded by a profile eroding at $1.5 \mathrm{~mm} \mathrm{ka}^{-1}$ (Fig. 6a). In a surface that has been exposed 449 for a period much shorter than $\sim 1 \mathrm{ka}$, the luminescence-depth profile is primarily a chronometer, 
450 because over this time span, the rate of migration of $x_{50 \%}$ into the rock is much greater than the rate of 451 removal of grains from the surface of the rock (Fig. 6a). Thus, a profile in this time zone can be fitted 452 by Eqn. 4 to determine the apparent exposure age of the surface. On the other hand, at times much 453 longer than the equilibrium age limit, the luminescence-depth profile is essentially an erosion-meter, 454 because it is in erosional steady state and has no memory of the exposure time. A profile in this time 455 zone can be modelled using Eqn. 8 to derive the erosion rate. There remains an intermediate transition 456 interval ( $\sim 0.3$ to $\sim 3 \mathrm{ka}$, points $\mathrm{A}$ and B in Fig. 6a) during which the luminescence-depth profile evolves 457 from being a chronometer to an erosion-meter. In order to derive either the apparent exposure age or 458 erosion rate in this transition period, a knowledge of the other parameter is required. In other words, to 459 determine the apparent exposure age from a profile in this time zone, the erosion rate must be known 460 independently, and vice versa.

461 In order to determine the equilibrium age range for various erosion rates, we have also simulated the 462 behavior of the erosion rate model (Eqn. 8) for a range of erosion rates from 0 to $1500 \mathrm{~mm} \mathrm{ka}^{-1}$. In 463 Figure $6 \mathrm{~b}$, the equilibrium ages for individual erosion rates are extrapolated onto the zero erosion rate 464 curve. For the erosion rates relevant to our samples $\left(0.015\right.$ to $\left.1.5 \mathrm{~mm} \mathrm{ka}^{-1}\right)$, luminescence-depth profiles 465 reach equilibrium after 44 to $1 \mathrm{ka}$ of exposure. These equilibrium age limits define the timescale to 466 which the corresponding erosion rates refer. For instance, an erosion rate of $0.015 \mathrm{~mm} \mathrm{ka}^{-1}$ is 467 effectively averaged over the last $44 \mathrm{ka}$ of surface exposure whereas an erosion rate of $1.5 \mathrm{~mm} \mathrm{ka}^{-1}$ is 468 only averaged over the last $1 \mathrm{ka}$. These luminescence-depth profiles have no memory of the erosion 469 history prior to these age limits.

470 Depending on the parameter values and the depth resolution, the $1 / \mu$ constraint can limit either the 471 minimum apparent exposure age or the maximum apparent erosion rate that can be derived from a 
472 luminescence-depth profile. The typical value of $\mu$ in our samples is between 0.5 and $1 \mathrm{~mm}^{-1}$ (Fig. 5), 473 meaning that the $x_{50 \%}$ point in the deepest profiles that can be reliably distinguished from the 474 bleaching/dose-rate steady-state profile must lie at least 1-2 mm shallower than the corresponding 475 point in the steady-state profile. Given the current resolution of sampling (i.e. slicing at $1.5 \mathrm{~mm}$ depth 476 intervals) and samples with typical parameter values, profiles with an apparent exposure age $<1$ a or an 477 apparent erosion rate $>1500 \mathrm{~mm} \mathrm{ka}^{-1}$ (see Fig. 6) cannot be modelled reliably as these would be 478 indistinguishable from steady-state. Collection of high-resolution data using spatially-resolved 479 luminescence imaging techniques (e.g. Greilich and Wagner, 2006) may help to overcome this 480 limitation in the future.

\section{Conclusion}

We have further developed the luminescence-surface exposure dating technique (Sohbati et al., 2012a,b) by taking the effect of rock surface erosion into account. The new model presented here (Eqn.

8) has been fitted to luminescence-depth profiles measured in subaerially exposed rock surfaces to give 485 centennial- to millennial-scale $\left(10^{2}-10^{4}\right.$ years $)$ hard rock erosion rates. The model predicts that the higher the erosion rate, the faster a luminescence-depth profile changes from being a (surface exposure) chronometer to an erosion rate meter. For example, for an erosion rate of $1.5 \mathrm{~mm} \mathrm{ka}^{-1}$ it takes only $\sim 3$ ka for a profile to become useful for deriving a unique erosion rate.

The application of the new model has been tested by fitting the IRSL-depth profiles measured into several glacial and landslide boulders in the Eastern Pamirs, China. The derived erosion rates for 7 out 491 of the 8 boulders sampled in this study vary between $<0.038 \pm 0.002$ and $1.72 \pm 0.04 \mathrm{~mm} \mathrm{ka}^{-1}$ (the eighth 492 boulder gave an anomalously high erosion rate, possibly due to a recent chipping/cracking loss of 493 surface). In the case of one sample with a low erosion rate of $0.09 \pm 0.02 \mathrm{~mm} \mathrm{ka}^{-1}$, we obtained an 
494 apparent luminescence surface exposure age of $11.6 \pm 2.3 \mathrm{ka}$, consistent with the ${ }^{10} \mathrm{Be}$ age of $9.9 \pm 0.9 \mathrm{ka}$ 495 for the same surface. This is the first time that a luminescence surface exposure age has been verified 496 by an independent age control.

497 Unfortunately, in the absence of an independent method that enables the measurement of erosion 498 rates over similar timescales (i.e. $10^{2}-10^{4}$ years), we cannot make any direct comparison between the 499 rates measured here and those estimated using other techniques in the literature. It is however 500 noteworthy that these luminescence erosion rates are only comparable with long-term $\mathrm{CN}$ erosion rates 501 reported for the most-slowly eroding outcrops in polar climates with a median erosion rate of $\sim 1 \mathrm{~m} \mathrm{Ma}^{-}$ $50{ }^{1}$ (Portenga and Bierman, 2011). One can speculate that the lower centennial- to millennial-scale 503 luminescence erosion rates derived here, when compared to the more typical $\mathrm{CN}$ rates measured in 504 non-polar environments (Portenga and Bierman, 2011), may reflect the deceleration of erosion rates 505 during the Holocene. However, any solid conclusion of this nature requires many more measurements 506 of luminescence erosion rates in different environments and lithologies.

\section{Acknowledgements}

508 This work was financially supported by the Aarhus University Research Foundation (AUFF 509 Pilotcenter for Quantitative Earth Surface Studies), the Carlsberg Foundation (Grant no. 2012_01 510 _0838), the National Natural Science Foundation of China (Grant no.: 41472161), and the State Key 511 Laboratory of Earthquake Dynamics (Grant no.: LED2013A09). BG was supported by the Netherlands 512 Organisation for Scientific Research (NWO) VENI grant 863.15.026. We would like to thank Dr. 513 Zhaode Yuan for providing us with his field photo of sample Muztagh-2. We thank Dr Nathan Brown 514 for the careful review of the manuscript. 


\section{Appendix A}

516 Consider Eqn. (7) from the main text:

$$
\frac{d n}{d t}=(N-n) F-n E_{0} e^{\mu \varepsilon t}
$$

517 To solve Eqn. (7), we introduce $\tau=(\mu \varepsilon)^{-1}$ and make use of dimensionless variables $r=n / N$,

$518 \quad a=F \tau$ and $v=E(x(t)) \tau=\tau E_{0} \exp (t / \tau)=v_{0} \exp (t / \tau)$, whose substitution into Eqn. (7) yields:

$\frac{d r}{d t}=\frac{a}{\tau}(1-r)-\frac{v}{\tau} r$

519 Dividing both sides of Eqn. (A.1) by the identity $d v / d t=v / \tau$ and rearranging results in:

$\frac{d r}{d v}+r\left(\frac{a}{v}+1\right)=\frac{a}{v}$

520 Eq. (A.2) is a first order non-homogeneous differential equation. Recast as $d r / d v+f(r) r=g(r)$, it

521 has a general solution $r=e^{-\int f(r) d x}\left\{\int e^{\int f(r) d x} g(r) d r+C\right\}$. Substituting $f(r)=a / v+1, g(r)=$

$522 a / v$, and integrating, we obtain:

$r=a v^{-a} e^{-v} \int_{v_{0}}^{v} u^{a-1} e^{u} d u$

523 where $u$ is a dummy integration variable. To obtain an analytical solution for Eqn. (A.3), we start with 524 the simple case of $v_{0}=0$ at $t=0$, i.e. an initially negligible optical loss coefficient in Eqn. (7) in a 525 mineral that is initially fully shielded from light. Using a power series to expand $e^{u}$ in the integrand, 526 we integrate and rearrange Eqn. (A.3) as follows: 


$$
\begin{gathered}
r(v)=a v^{-a} e^{-v} \int_{0}^{v} u^{a-1}\left(1+\frac{u}{1 !}+\frac{u^{2}}{2 !}+\cdots\right) d u=a v^{-a} e^{-v}\left(\frac{v^{a}}{a}+\frac{v^{a+1}}{(a+1) 1 !}+\frac{v^{a+2}}{(a+2) 2 !}+\cdots\right) \\
=e^{-v}\left(1+\frac{a}{(a+1) 1 !} v+\frac{a}{(a+2) 2 !} v^{2}+\cdots\right) \\
=e^{-v}\left(1+\frac{a}{(a+1) 1 !} v+\frac{a(a+1)}{(a+1)(a+2) 2 !} v^{2}+\cdots\right)
\end{gathered}
$$

527 Making the substitutions $z=v, m=a$ and $n=a+1$, we notice that the power series in Eqn. (A.4) 528 conforms to the confluent hypergeometric function (Abramowitz and Stegun, 1964):

$M(m, n, z)=\left(1+\frac{m}{n \cdot 1 !} z+\frac{m(m+1)}{n(n+1) 2 !} z^{2}+\cdots\right)$

529 which efficiently reduces Eqn. (A.4) to:

$r(v)=e^{-v} M(a, a+1, v)$

530 To further simplify Eqn. (A. 6), we apply Kummer's theorem $M(m, n, z)=e^{z} M(n-m, n,-z)$, which 531 reduces Eqn. (A.6) to the desired form:

$r(v)=M(1,1+a,-v)$

532 Remembering that $\tau=(\mu \varepsilon)^{-1}$, by substituting the dimensionless variables by physical variables, i.e. $533 r=n / N, a=F \tau$, and $v=E(x) \tau$ into Eqn. (A.7), for $x=x_{0}-\varepsilon t$ we obtain:

$\frac{n(x, \varepsilon)}{N}=M\left(1,1+\frac{F}{\mu \varepsilon}, \frac{-E(x)}{\mu \varepsilon}\right)$

534 which is the same as Eqn. (8) in the main text, and describes luminescence systems exhuming towards 535 the present-day surface from initially photon-impenetrable depths $\left(E_{0}=0\right)$. The confluent 536 hypergeometric function $M(m, n, z)$ is readily available in all common modelling software, either as an 537 in-built function (e.g. Matlab, Mathematica) or as an optional extension (e.g. Excel, OriginLab). If 
538 nevertheless in need to numerically evaluate $M(m, n, z)$ using series expansion, consult Abramowitz 539 and Stegun (1964).

540 The treatment can be further extended to include an arbitrary $E_{0} \geq 0$, i.e. an initial boundary 541 condition $0 \leq v 0<v$. To do this, we first expand Eqn. (A.3) into:

$r=a v^{-a} e^{-v} \int_{v_{0}}^{v} u^{a-1} e^{u} d u=a v^{-a} e^{-v} \int_{0}^{v} u^{a-1} e^{u} d u-a v^{-a} e^{-v} \int_{0}^{v_{0}} u^{a-1} e^{u} d u$

542 We now use the previously-derived identity (Eqns. A.3 and A.7):

$a v^{-a} e^{-v} \int_{0}^{v} u^{a-1} e^{u} d u=M(1,1+a,-v)$

543 to express the last integral in Eqn. (A.9) as:

$\int_{0}^{v_{0}} u^{a-1} e^{u} d u=a^{-1} v_{0}^{a} e^{v_{0}} M\left(1,1+a,-v_{0}\right)$

544 By substitution of the two identities above in to Eqn. (A.9), we obtain the desired form:

$r(v)=M(1,1+a,-v)-a v^{-a} e^{-v}\left[a^{-1} v_{0}^{a} e^{v_{0}} M\left(1,1+a,-v_{0}\right)\right]$

545

$$
=M(1,1+a,-v)-\left(v_{0} / v\right)^{a} e^{v_{0}-v} M\left(1,1+a,-v_{0}\right)
$$




\section{References}

547 Abramowitz, M., Stegun, I., 1964. Handbook of mathematical functions: with formulas, graphs, and 548 mathematical tables. Vol. 55. Courier Corporation.

549 Aitken, M.J., 1985. Thermoluminescence dating, Studies in Archaeological Science.

550 Aitken, M.J., 1998. An introduction to optical dating: The dating of Quaternary sediments by the use of 551 photon-stimulated luminescence, Oxford science publications. doi:10.1002/(SICI)1520$552 \quad 6548(200001) 15: 1<81:: A I D-G E A 5>3.3 . C O ; 2-Y$

553 Balco, G., Stone, J.O., Lifton, N.A., Dunai, T.J., Lifton, A., Dunai, T.J., 2008. A complete and easily 554 accessible means of calculating surface exposure ages or erosion rates from $10 \mathrm{Be}$ and $26 \mathrm{Al}$ 555 measurements. Quat. Geochronol. 3, 174-195. doi:10.1016/j.quageo.2007.12.001

556 Baril, M.R., Huntley, D.J., 2003. Infrared stimulated luminescence and phosphorescence spectra of 557 irradiated feldspars. J. Phys. Condens. Matter 15, 8029-8048. doi:10.1088/0953-8984/15/46/018

558 Borchers, B., Marrero, S., Balco, G., Caffee, M., Goehring, B., Lifton, N., Nishiizumi, K., Phillips, F., 559 Schaefer, J., Stone, J., 2016. Geological calibration of spallation production rates in the CRONUS560 Earth project. Quat. Geochronol. 31, 188-198. doi:10.1016/j.quageo.2015.01.009

561 Braun, J., Van Der Beek, P., Batt, G., 2006. Quantitative thermochronology: numerical methods for the 562 interpretation of thermochronological data. Cambridge University Press. 
563 Gardner, T.W., Jorgensen, D.W., Shuman, C., Lemieux, C.R., 1987. Geomorphic and tectonic process 564 rates: effects of measured time interval. Geology 15, 259-261. doi:10.1130/0091565 7613(1987)15<259:GATPRE >2.0.CO

566 Greilich, S., Wagner, G.A., 2006. Development of a spatially resolved dating technique using HR-OSL. 567 Radiat. Meas. 41, 738-743. doi:10.1016/j.radmeas.2006.05.022

568 Guérin, G., Mercier, N., Adamiec, G., 2011. Dose-rate conversion factors: update. Anc. TL 29, 5-8.

569 Guralnik, B., Jain, M., Herman, F., Paris, R.B., Harrison, T.M., Murray, A.S., Valla, P.G., Rhodes, 570 E.J., 2013. Effective closure temperature in leaky and/or saturating thermochronometers. Earth Planet. 571 Sci. Lett. 384, 209-218. doi:10.1016/j.epsl.2013.10.003

572 Guralnik, B., Ankjærgaard, C., Jain, M., Murray, A.S., Müller, a., Wälle, M., Lowick, S.E., Preusser, 573 F., Rhodes, E.J., Wu, T.-S., Mathew, G., Herman, F., 2015. OSL-thermochronometry using bedrock 574 quartz: A note of caution. Quat. Geochronol. 25, 37-48. doi:10.1016/j.quageo.2014.09.001

575 Habermann, J., Schilles, T., Kalchgruber, R., Wagner, G.A., 2000. Steps towards surface dating using 576 luminescence. Radiat. Meas. 32, 847-851. doi:10.1016/S1350-4487(00)00066-4

577 Huntley, D.J., Hancock, G.V., 2001. The Rb contents of the K-feldspar grains being measured in 578 optical dating. Anc. TL 19, 43-46.

579 Huntley, D.J., 2006. An explanation of the power-law decay of luminescence. J. Phys. Condens. Matter 580 18, 1359-1365. doi:10.1088/0953-8984/18/4/020 
581 Kirchner, J.W., Finkel, R.C., Riebe, C.S., Granger, D.E., Clayton, J.L., King, J.G., Megahan, W.F., 582 Sites, F., 2001. Mountain erosion over 10 yr, 10 k.y., and 10 m.y. time scales. Geology 29, 591-594. 583 doi:10.1130/0091-7613(2001)029<0591:MEOYKY>2.0.CO;2

584 Koppes, M.N., Montgomery, D.R., 2009. The relative efficacy of fluvial and glacial erosion over 585 modern to orogenic timescales. Nat. Geosci. 2, 644-647. doi:10.1038/ngeo616

586 Lal, D., 1991. Cosmic ray labeling of erosion surfaces: in situ nuclide production rates and erosion 587 models. Earth Planet. Sci. Lett. 104, 424-439. doi:10.1016/0012-821X(91)90220-C

588 Lal, D., Gallup, C.D., Somayajulu, B.L.K., Vacher, L., Caffee, M.W., Jull, A.J.T., Finkel, R.C., Speed, 589 R.C., Winter, A., 2005. Records of cosmogenic radionuclides ${ }^{10} \mathrm{Be},{ }^{26} \mathrm{Al}$ and ${ }^{36} \mathrm{Cl}$ in corals: First studies 590 on coral erosion rates and potential of dating very old corals. Geochim. Cosmochim. Acta 69, 5717591 5728. doi:10.1016/j.gca.2005.08.012

592 Lamothe, M., Auclair, M., Hamzaoui, C., Huot, S., 2003. Towards a prediction of long-term anomalous 593 fading of feldspar IRSL. Radiat. Meas. 37, 493-498. doi:10.1016/S1350-4487(03)00016-7

594 Laskaris, N., Liritzis, I., 2011. A new mathematical approximation of sunlight attenuation in rocks for 595 surface luminescence dating. J. Lumin. 131, 1874-1884. doi:10.1016/j.jlumin.2011.04.052

596 Lehmann, B., Valla, P.G., King, G.E., Herman, F., 2018. Investigation of OSL surface exposure dating 597 to reconstruct post-LIA glacier fluctuations in the French Alps (Mer de Glace, Mont Blanc massif). 598 Quat. Geochronol. 44, 63-74. doi:10.1016/j.quageo.2017.12.002 
599 Liu, J., Sohbati, R., Murray, A.S., Jain, M., Andersen, J.L., Egholm, D.L., Linge, H., Chen, J., Luo, M., 600 Zheng, R., in review. Luminescence rock-surface dating reveals complex depositional histories of 601 glacial and landslide boulders. Earth Planet. Sci. Lett.

602 Mejdahl, V., 1987. Internal radioactivity in quartz and feldspar grains. Anc. TL 5, 10-17.

603 Moses, C., Robinson, D., Barlow, J., 2014. Methods for measuring rock surface weathering and 604 erosion: A critical review. Earth-Science Rev. 135, 141-161. doi:10.1016/j.earscirev.2014.04.006

605 Murray, A.S., Marten, R., Johnson, A., Martin, P., 1987. Analysis for naturally-occurring radionuclides 606 at environmental concentrations by gamma spectrometry. J. Radioanal. Nucl. Chem. 115, $263-288$.

607 Nishiizumi, K., Lal, D., Klein, J., Middleton, R., Arnold, J., 1986. Production of ${ }^{10}$ Be and ${ }^{26} \mathrm{Al}$ by 608 cosmic rays in terrestrial quartz in-situ and implications for erosion rates. Nature 319, $134-136$. 609 doi:http://dx.doi.org/10.1038/319134a0

610 Owen, L.A., Chen, J., Hedrick, K.A., Caffee, M.W., Robinson, A.C., Schoenbohm, L.M., Yuan, Z., Li, 611 W., Imrecke, D.B., Liu, J., 2012. Quaternary glaciation of the Tashkurgan Valley, Southeast Pamir. 612 Quat. Sci. Rev. 47, 56-72. doi:10.1016/j.quascirev.2012.04.027

613 Pederson, J.L., Chapot, M.S., Simms, S.R., Sohbati, R., Rittenour, T.M., Murray, A.S., Cox, G., 2014. 614 Reply to Simon and Reed: Independent and converging results rule out historic disturbance and 615 confirm age constraints for Barrier Canyon rock art. Proc. Natl. Acad. Sci. 111, E5604-E5604. 616 doi:10.1073/pnas.1421319112 
617 Portenga, E.W., Bierman, P.R., 2011. Understanding earth's eroding surface with ${ }^{10}$ Be. GSA Today 21, 618 4-10. doi:10.1130/G111A.1

619 Prescott, J.R., Hutton, J.T., 1994. Cosmic ray contributions to does rates for Luminescence and ESR 620 dating: large depths and long-terms variations. Radiat. Meas. 23, 497-500.

621 Sanderson, D., Smillie, M., McCullagh, R., Feathers, J., Hauser, N., 2011. Surface exposure dating by 622 luminescence: developing and testing models for surface bleaching rates and erosion rates. 13th 623 International Conference on Luminescence and Electron Spin Resonance Dating, 10-14 July 2011, 624 Torun, Poland, Book of Abstracts, p. 178.

625 Schumm, S.A., Lichty, R.W., 1965. Time, space, and causality in geomorphology. Am. J. Sci. 626 doi:10.2475/ajs.263.2.110

627 Seong, Y.B., Owen, L.A., Yi, C., Finkel, R.C., 2009a. Quaternary glaciation of Muztag Ata and 628 Kongur Shan: Evidence for glacier response to rapid climate changes throughout the late glacial and 629 holocene in westernmost Tibet. Bull. Geol. Soc. Am. 121, 348-365. doi:10.1130/B26339.1

630 Seong, Y.B., Owen, L. A., Yi, C., Finkel, R.C., Schoenbohm, L., 2009b. Geomorphology of 631 anomalously high glaciated mountains at the northwestern end of Tibet: Muztag Ata and Kongur Shan. 632 Geomorphology 103, 227-250. doi:10.1016/j.geomorph.2008.04.025

633 Shao, Y., 2009. Physics and Modelling of Wind Erosion, Physics and Modelling of Wind Erosion. 634 Springer Netherlands, Dordrecht. doi:10.1007/978-1-4020-8895-7_4 
635 Sohbati, R., Murray, A.S., Jain, M., Buylaert, J.-P., Thomsen, K.J., 2011. Investigating the resetting of 636 OSL signals in rock surfaces. Geochronometria 38, 249-258. doi:10.2478/s13386-011-0029-2

637 Sohbati, R., Murray, A.S., Chapot, M.S., Jain, M., Pederson, J., 2012a. Optically stimulated 638 luminescence (OSL) as a chronometer for surface exposure dating. J. Geophys. Res. 117, B09202. 639 doi:10.1029/2012JB009383

640 Sohbati, R., Jain, M., Murray, A., 2012b. Surface exposure dating of non-terrestrial bodies using 641 optically stimulated luminescence: A new method. Icarus 221, 160-166.

642 Sohbati, R., Murray, A.S., Buylaert, J.-P., Almeida, N. A. C., Cunha, P.P., 2012c. Optically stimulated 643 luminescence (OSL) dating of quartzite cobbles from the Tapada do Montinho archaeological site 644 (east-central Portugal). Boreas 41, 452-462. doi:10.1111/j.1502-3885.2012.00249.x

645 Sohbati, R., Murray, A.S., Porat, N., Jain, M., Avner, U., 2015. Age of a prehistoric "Rodedian” cult 646 site constrained by sediment and rock surface luminescence dating techniques. Quat. Geochronol. 30, 647 90-99. doi:10.1016/j.quageo.2015.09.002

648 Spilde, M.N., Melim, L.A., Northup, D.E., Boston, P.J., 2013. Anthropogenic lead as a tracer of rock 649 varnish growth: Implications for rates of formation. Geology 41, 263-266. doi:10.1130/G33514.1

650 Stone, J.O., 2000. Air pressure and cosmogenic isotope production. J. Geophys. Res. 105759, 753-23. 651 doi:10.1029/2000JB900181 
652 Stephenson, W.J., Finlayson, B.L., 2009. Measuring erosion with the micro-erosion meter653 Contributions to understanding landform evolution. Earth-Science Rev. 95, 53-62. 654 doi:10.1016/j.earscirev.2009.03.006

655 Turowski, J.M., Cook, K.L., 2017. Field techniques for measuring bedrock erosion and denudation. 656 Earth Surf. Process. Landforms 42, 109-127. doi:10.1002/esp.4007

657 Xu, X., Yi, C., 2014. Little Ice Age on the Tibetan Plateau and its bordering mountains: Evidence from 658 moraine chronologies. Glob. Planet. Change 116, 41-53. doi:10.1016/j.gloplacha.2014.02.003

659 Yuan, Z., Chen, J., Owen, L.A., Hedrick, K.A., Caffee, M.W., Li, W., Schoenbohm, L.M., Robinson, 660 A.C., 2013. Nature and timing of large landslides within an active orogen, eastern Pamir, China. 661 Geomorphology 182, 49-65. doi:10.1016/j.geomorph.2012.10.028

662 Viles, H.A., 2001. Scale issues in weathering studies. Geomorphology 41, 63-72. doi:10.1016/S0169$663555 X(01) 00104-0$

664 Wallinga, J., Murray, A., Wintle, A., 2000. The single-aliquot regenerative-dose (SAR) protocol 665 applied to coarse-grain feldspar. Radiat. Meas. 32, 529-533. doi:10.1016/S1350-4487(00)00091-3

666 Wallinga, J., Bos, A.J.J., Dorenbos, P., Murray, A.S., Schokker, J., 2007. A test case for anomalous 667 fading correction in IRSL dating. Quat. Geochronol. 2, 216-221. doi:10.1016/j.quageo.2006.05.014

668 Warke, P.A., McKinley, J.M., 2011. Scale issues in geomorphology. Geomorphology 130, 1-4. 669 doi:10.1016/j.geomorph.2011.04.031 
670 Wintle, A., Murray, A.S., 2006. A review of quartz optically stimulated luminescence characteristics

671 and their relevance in single-aliquot regeneration dating protocols. Radiat. Meas. 41, 369-391. 672 doi:10.1016/j.radmeas.2005.11.001 
674 Figure 1) Model luminescence-depth profiles as predicted by Eqns (4) and (8) for (a) a non-eroding 675 and (b) an eroding rock surface, respectively. The selected parameter values are $\dot{D}=6 \mathrm{~Gy} \mathrm{ka}^{-1}, D_{o}=$ $676250 \mathrm{~Gy}, \overline{\sigma \varphi_{0}}=2200 \mathrm{ka}^{-1}$ and $\mu=0.6 \mathrm{~mm}^{-1}$ comparable to the average values obtained for the samples 677 used in this study.

678

679 Figure 2) Study area and sampling sites, Southeast Pamir, China. Glacial and landslide boulders were 680 resampled from three different sites along the Tashkurgan valley. The age ranges represent the ${ }^{10} \mathrm{Be}$ 681 ages of boulder surfaces previously determined by Seong et al. (2009a) (8-9 ka), Yuan et al. (2013) 682 (14-15 ka) and Owen et al. (2012) (65-87 ka).

683

684 Figure 3) View of the boulders sampled for this study. The red arrows point to the sample locations. 685

686 Figure 4) (a) View of Muztagh-2 ${ }^{10}$ Be sample previously taken by Yuan et al. (2013) in 2010. (b) 687 View of the same sample as in (a) sampled in 2013 as non-eroding known-age sample for calibration of 688 luminescence-depth profiles. (c) Variation of the normalized natural sensitivity-corrected IRSL residual 689 signal $\left(\mathrm{L}_{\mathrm{n}} / \mathrm{T}_{\mathrm{n}}\right)$ with depth into $\left.\mathrm{i}\right)$ the bottom of a $>2$-cm deep chiseled surface where Muztagh-2 ${ }^{10} \mathrm{Be}$ 690 sample had been collected (red circles), and ii) the natural varnished surface of the boulder (black 691 circles). Each data point represents the signal measured from at least one whole rock slice coming from 692 a certain depth into the boulder and thus represents the average luminescence at that depth. The error 693 bars represent one standard error. For normalization, the $\mathrm{L}_{\mathrm{n}} / \mathrm{T}_{\mathrm{n}}$ value of each slice was divided by the 694 average of saturated $\mathrm{L}_{\mathrm{n}} / \mathrm{T}_{\mathrm{n}}$ values measured from depths $>20 \mathrm{~mm}$ (i.e. depths in field saturation) in the 
695 corresponding profile. The solid lines show the best simultaneous fits to both data sets using Eqn. 4 696 with the surface bleaching rate $\overline{\sigma \varphi_{0}}$ and the light attenuation coefficient $\mu$ as shared parameters 697 between the two fits. The fittings were done using Poisson weighting $\left(w_{i}=1 / y_{i}\right)$.

698

699 Figure 5) Variation of the normalized natural sensitivity-corrected IRSL signal $\left(\mathrm{L}_{\mathrm{n}} / \mathrm{T}_{\mathrm{n}}\right)$ with depth in 700 all samples. Each data point is an average of the residual signal measured from at least three intact rock 701 slices of the same depth coming from parallel cores ( $<5 \mathrm{~cm}$ apart) drilled into the same surface. The 702 error bars represent one standard error. The normalization factor was obtained by averaging the $L_{n} / T_{n}$ 703 values at depths $>20 \mathrm{~mm}$ (i.e. depths in field saturation) for individual profiles. The visually704 indistinguishable overlapping solid lines indicate the best fits of Eqns. 4 and 8 to the data points, 705 resulting in the apparent luminescence surface-exposure age and erosion rate as model parameters. $\overline{\sigma \varphi_{0}}$ 706 was set to $2165 \mathrm{ka}^{-1}$ as the shared parameter value between all the fits and $\mu$ was free to float as the 707 sample-dependent parameter. $\dot{D}$ and $D_{o}$ had the same values as in Table 1 . The fittings were performed 708 using Poisson weighting $\left(w_{i}=1 / y_{i}\right)$. The dashed and dotted lines represent erosion-free model 709 profiles obtained by replacing the time in Eqn. 4 with (i) the ${ }^{10} \mathrm{Be}$ age of the same surface and (ii) 710 infinity.

712 Figure 6) The model dependence of luminescence-depth profiles on erosion rate and exposure time. (a) 713 Profiles generated by setting $t$ in Eqn. 4 to a particular age (from 0.1 a to $100 \mathrm{ka}$ ) and then fitting these 714 modelled profiles with Eqn. (8) using erosion rates of 0 and $1.5 \mathrm{~mm} \mathrm{ka}^{-1}$. The equilibrium age limit (see 715 text) is indicated by the extrapolation of the steady-state part of the $1.5 \mathrm{~mm} \mathrm{ka}^{-1}$ curve onto the zero 716 erosion rate curve. The transition zone between the time ranges in which the profile eroding at $1.5 \mathrm{~mm}$ 
$717 \mathrm{ka}^{-1}$ acts as chronometer or an erosion-meter is indicated by the points A and B arbitrarily defined to lie $71810 \%$ within the chronometer and erosion-meter parts of the $1.5-\mathrm{mm} \mathrm{ka}^{-1}$ curve, respectively. (b) 719 Modelled profiles generated as in (a) but using different erosion rates between 0 and $1500 \mathrm{~mm} \mathrm{ka}^{-1}$, 720 showing their respective equilibrium ages on the zero erosion rate curve. 
722 Table 1) Summary of samples, model parameter values, luminescence surface-exposure ages and 723 erosion rates. All the ${ }^{10} \mathrm{Be}$ ages were calculated using the CRONUS online calculator version 2.3 724 (Balco et al., 2008) with high latitude/sea level production rate of 4.01 (Borcher et al., 2016), assuming 725 standard atmosphere, zero erosion and the time-dependent Lal/Stone (2000) spallation scaling scheme, 726 and are normalized to the "07KNSTD" isotope ratio standardization. The uncertainties include errors 727 associated with scaling and calibration (external uncertainty). 

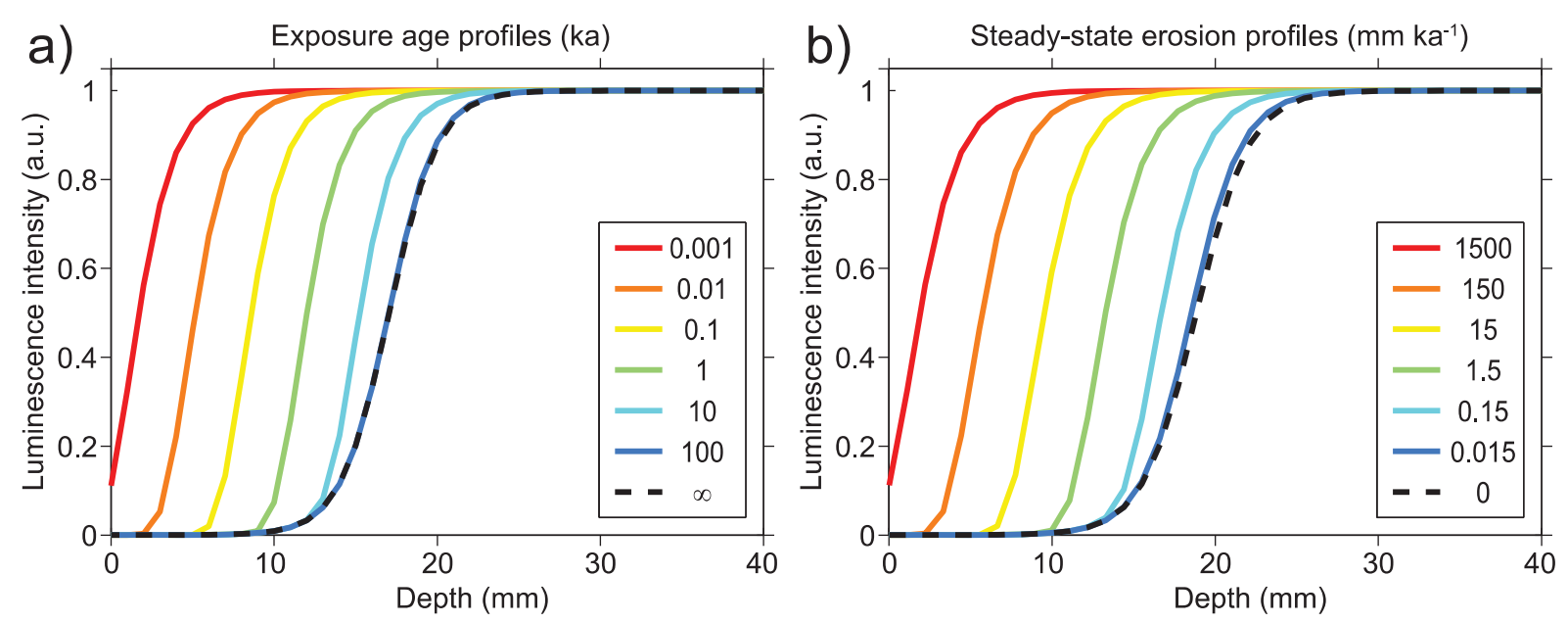

\section{$728 \quad$ Figure 1)}



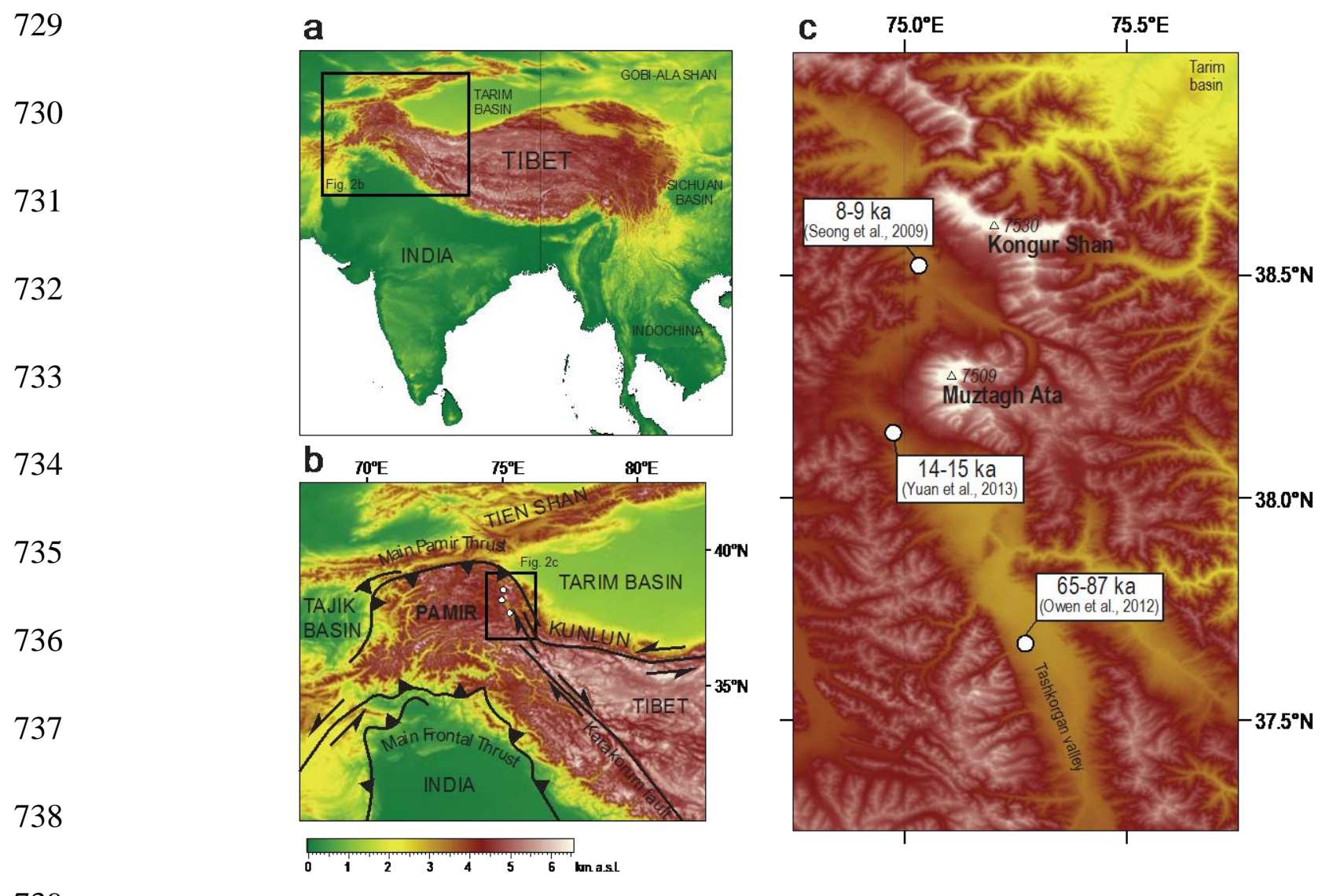

739

$740 \quad$ Figure 2) 

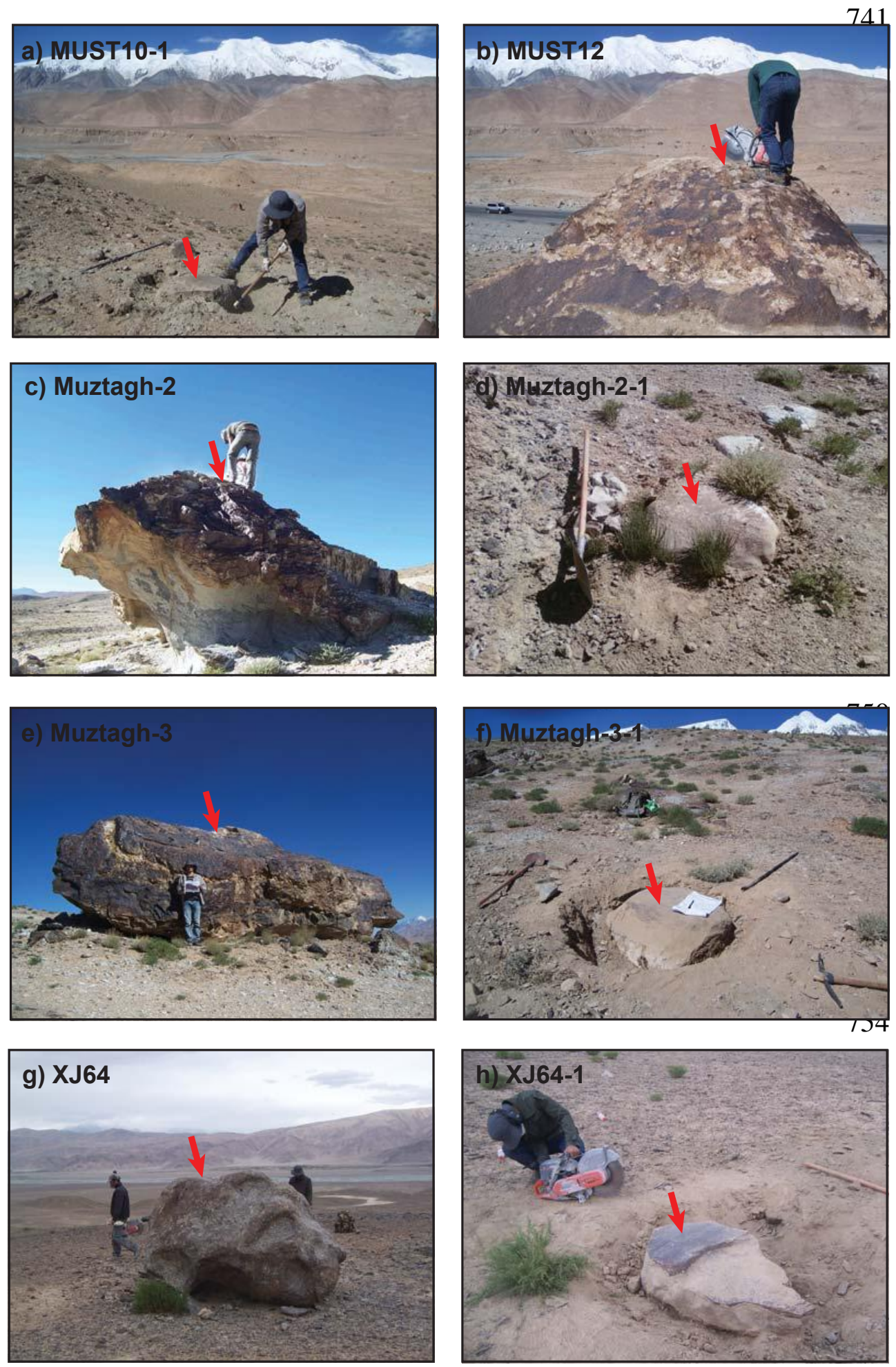

\section{$759 \quad$ Figure 3)}


a) ${ }^{10} \mathrm{Be}$ sampling

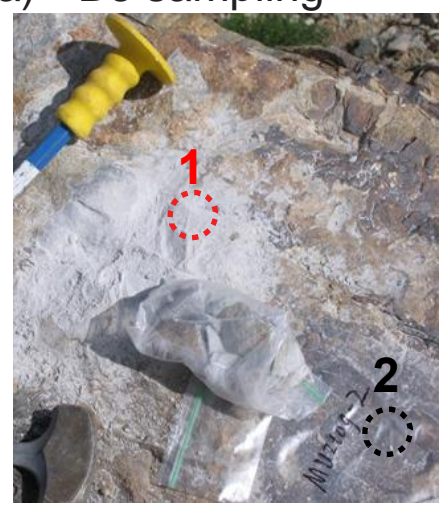

August 2010 b) OSL sampling

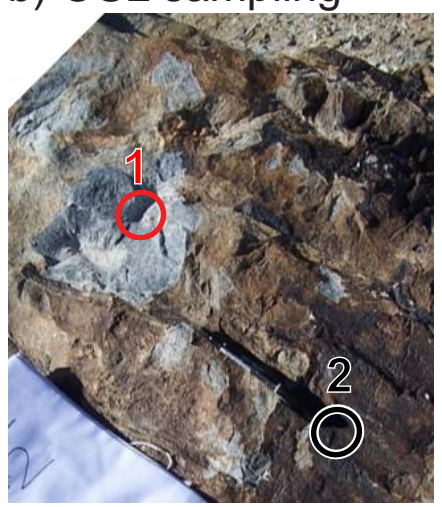

July 2013 c) OSL depth profiles

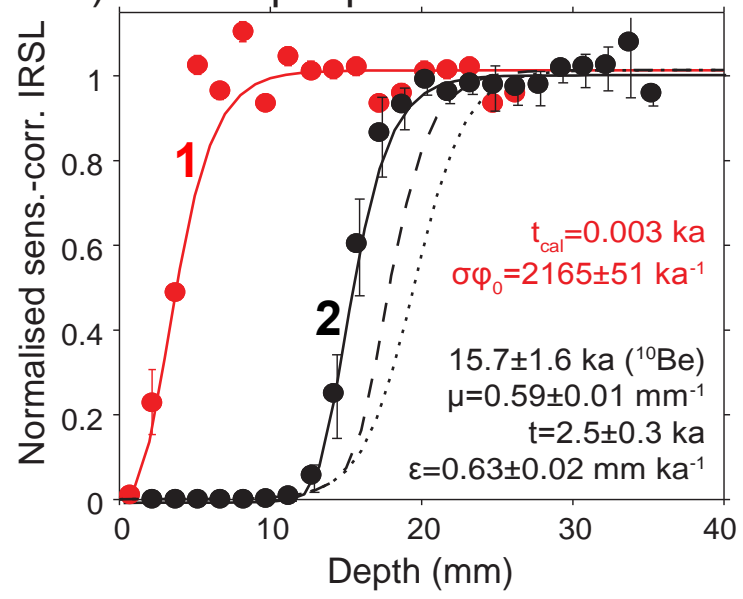

\section{$760 \quad$ Figure 4)}



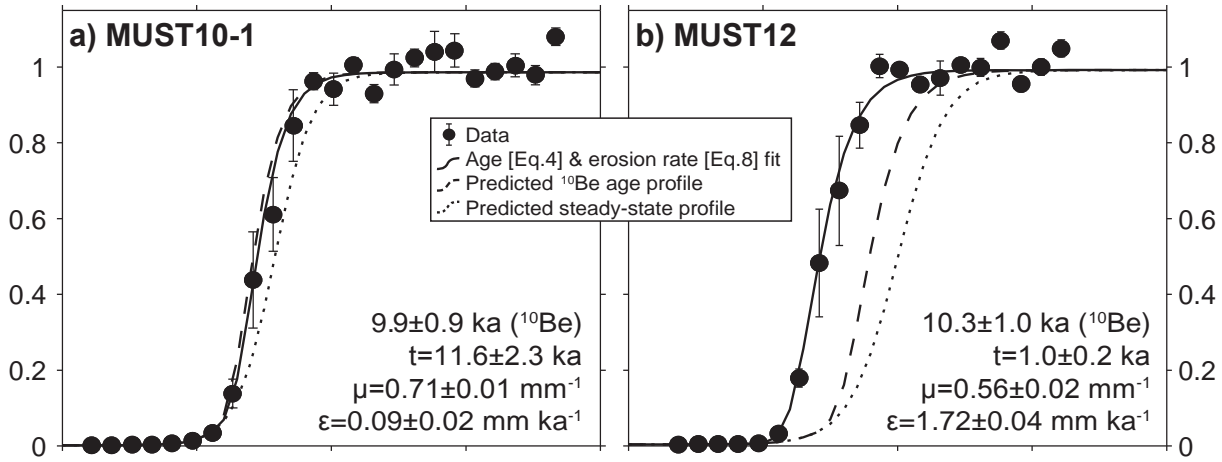

765
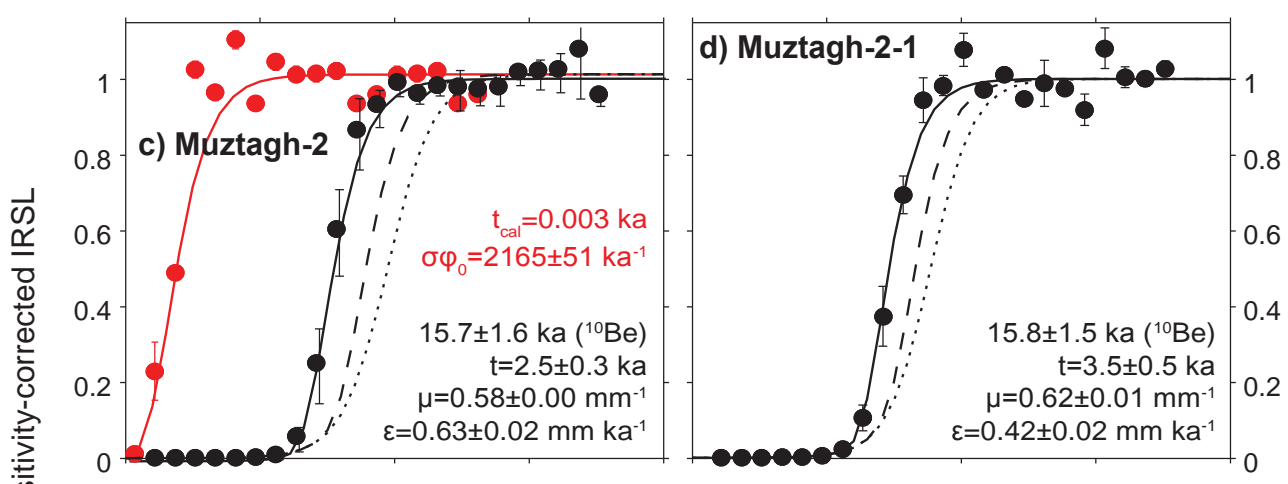

769

770

771

772
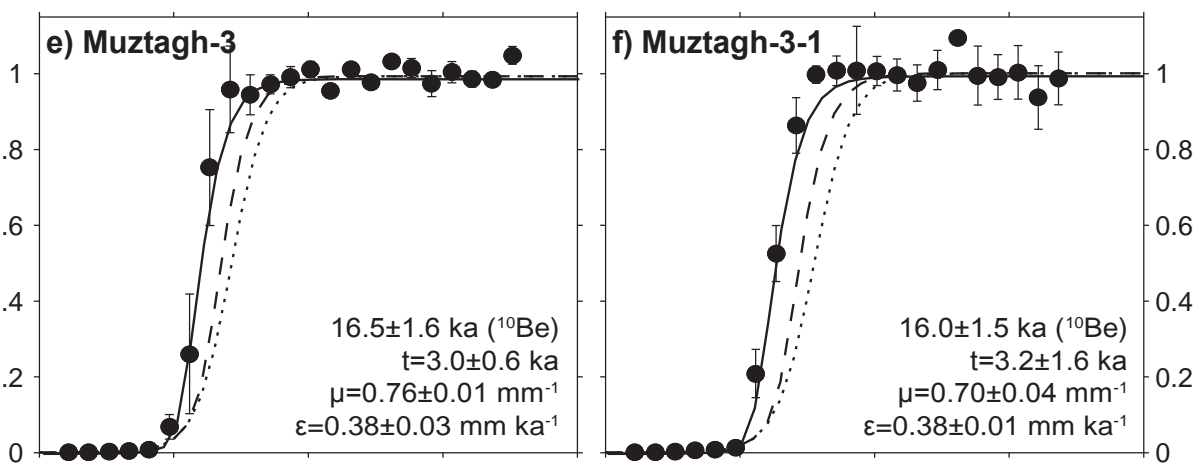

774
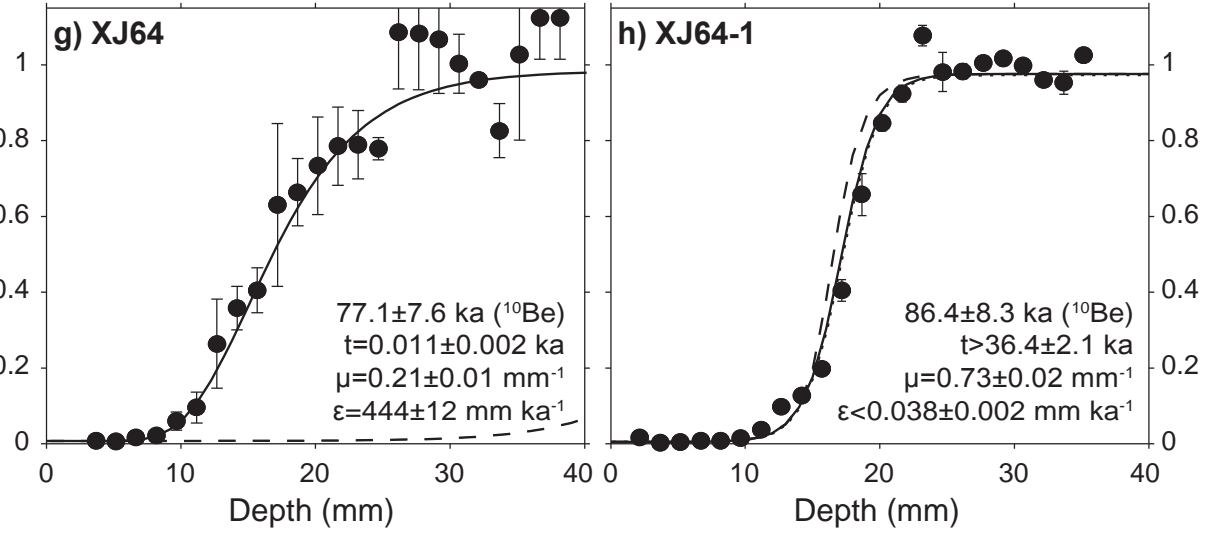

779

Figure 5) 

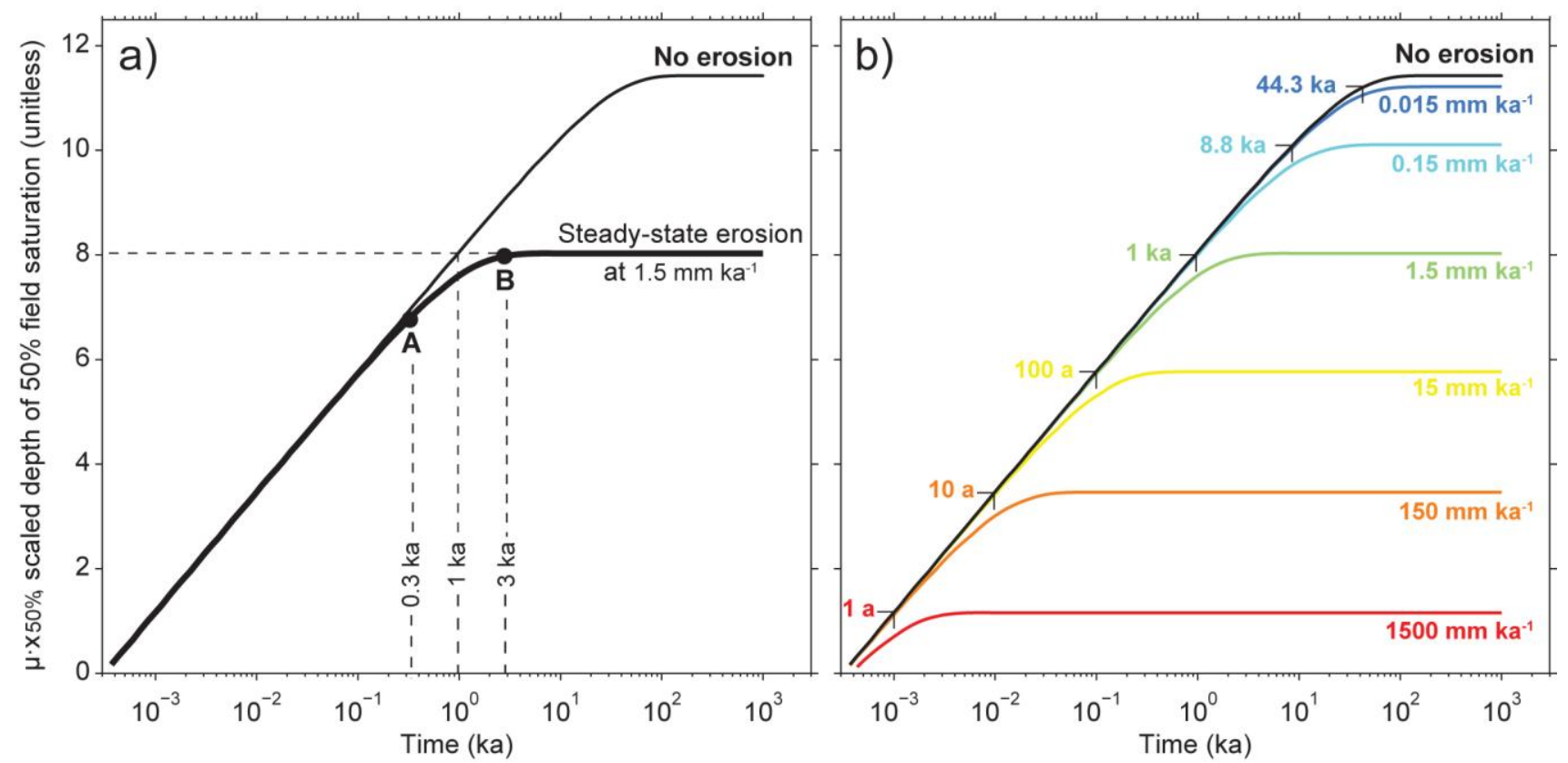

\section{$780 \quad$ Figure 6)}




\begin{tabular}{|c|c|c|c|c|c|c|c|c|c|c|}
\hline \multirow{2}{*}{$\begin{array}{c}\text { Sample } \\
\text { name }\end{array}$} & \multirow[b]{2}{*}{ Landform } & \multirow[b]{2}{*}{ Lithology } & \multirow{2}{*}{$\dot{D}$} & \multirow{2}{*}{$D_{0}$} & \multicolumn{2}{|c|}{ Age model } & \multicolumn{2}{|c|}{ Erosion rate model } & \multirow{2}{*}{$\begin{array}{l}\text { Published } \\
{ }^{10} \text { Be age }\end{array}$} & \multirow[t]{2}{*}{${ }^{10} \mathrm{Be}$ age Reference } \\
\hline & & & & & $\mu$ & age & $\mu$ & erosion rate & & \\
\hline & & & $\left(\mathrm{Gy} \mathrm{ka}^{-1}\right)$ & (Gy) & $\mathrm{mm}^{-1}$ & $\mathrm{ka}$ & $\mathrm{mm}^{-1}$ & $\mathrm{~mm} \mathrm{ka}^{-1}$ & $\mathrm{ka}$ & \\
\hline & & & \pm se & $\pm \mathrm{se}$ & $\pm \mathrm{se}$ & $\pm \mathrm{se}$ & $\pm \mathrm{se}$ & \pm se & $\pm \mathrm{se}$ & \\
\hline$\overline{\text { MUST10-1 }}$ & Moraine & Granite gneiss & $7.99 \pm 0.14$ & $276 \pm 23$ & $0.71 \pm 0.01$ & $11.6 \pm 2.3$ & $0.71 \pm 0.01$ & $0.09 \pm 0.02$ & $9.9 \pm 0.9$ & Liu et al. (in review) \\
\hline MUST12 & Moraine & Granite gneiss & $6.98 \pm 0.15$ & $264 \pm 7$ & $0.56 \pm 0.02$ & $1.0 \pm 0.2$ & $0.56 \pm 0.02$ & $1.72 \pm 0.04$ & $10.3 \pm 1.0^{*}$ & Seong et al. (2009a) \\
\hline MUZTAGH-2 & Landslide & Granite gneiss & $5.45 \pm 0.09$ & $238 \pm 34$ & $0.59 \pm 0.01$ & $2.5 \pm 0.3$ & $0.58 \pm 0.00$ & $0.63 \pm 0.02$ & $15.7 \pm 1.6^{*}$ & Yuan et al. (2013) \\
\hline MUZTAGH-2-1 & Landslide & Granite gneiss & $6.49 \pm 0.10$ & $214 \pm 16$ & $0.63 \pm 0.01$ & $3.5 \pm 0.5$ & $0.62 \pm 0.01$ & $0.42 \pm 0.02$ & $15.8 \pm 1.5$ & Liu et al. ( in review ) \\
\hline MUZTAGH-3 & Landslide & Granite gneiss & $6.19 \pm 0.11$ & $176 \pm 12$ & $0.77 \pm 0.01$ & $3.0 \pm 0.6$ & $0.76 \pm 0.01$ & $0.38 \pm 0.03$ & $16.5 \pm 1.6^{*}$ & Yuan et al. (2013) \\
\hline MUZTAGH-3-1 & Landslide & Granite gneiss & $6.23 \pm 0.11$ & $225 \pm 13$ & $0.73 \pm 0.03$ & $3.2 \pm 1.6$ & $0.70 \pm 0.04$ & $0.38 \pm 0.01$ & $16.0 \pm 1.5$ & Liu et al. (in review ) \\
\hline XJ64 & Moraine & Granodiorite & $7.33 \pm 0.15$ & $245 \pm 18^{* *}$ & $0.21 \pm 0.01$ & $0.011 \pm 0.002$ & $0.21 \pm 0.01$ & $444 \pm 12$ & $77.1 \pm 7.6^{*}$ & Owen et al. (2012) \\
\hline XJ64-1 & Moraine & Quartzite & $2.72 \pm 0.06$ & $320 \pm 12$ & $0.73 \pm 0.02$ & $>36.4 \pm 2.1$ & $0.73 \pm 0.02$ & $<0.038 \pm 0.002$ & $86.4 \pm 8.3$ & Liu et al. (in review) \\
\hline
\end{tabular}

$782{ }^{*}$ The age was recalculated for consistency with those in Liu et al. (in review).

$783{ }^{* *}$ No $D_{o}$ was measured for this sample. This is an average of the $D_{0}$ values measured for the other samples.

\section{Table 1)}




\section{Supplementary material}

\begin{tabular}{lccccccc}
\hline $\begin{array}{l}\text { Sample } \\
\text { Name }\end{array}$ & ${ }^{238} \mathrm{U}$ & ${ }^{226} \mathrm{Ra}$ & ${ }^{232} \mathrm{Th}$ & ${ }^{40} \mathrm{~K}$ & $\begin{array}{c}\text { Beta } \\
\text { dose rate }\end{array}$ & $\begin{array}{c}\text { Gamma } \\
\text { dose rate }\end{array}$ & $\begin{array}{c}\text { Mean K-felds } \\
\text { grain size }\end{array}$ \\
\hline & $\begin{array}{c}\left(\mathrm{Bq} \mathrm{kg}^{-1}\right) \\
\pm \mathrm{se}\end{array}$ & $\begin{array}{c}\left(\mathrm{Bq} \mathrm{kg}^{-1}\right) \\
\pm \mathrm{se}\end{array}$ & $\begin{array}{c}\left(\mathrm{Bq} \mathrm{kg}^{-1}\right) \\
\pm \mathrm{se}\end{array}$ & $\begin{array}{c}\left(\mathrm{Bq} \mathrm{kg}^{-1}\right) \\
\pm \mathrm{se}\end{array}$ & $\begin{array}{c}\left(\mathrm{Gy} \mathrm{ka}^{-1}\right) \\
\pm \mathrm{se}\end{array}$ & $\begin{array}{c}\left(\mathrm{Gy} \mathrm{ka}^{-1}\right) \\
\pm \mathrm{se}\end{array}$ & $\mu \mathrm{m}$ \\
\hline MUST10-1 & $73 \pm 9$ & $109.1 \pm 1.2$ & $146.2 \pm 1.2$ & $1274 \pm 22$ & $3.39 \pm 0.06$ & $3.48 \pm 0.09$ & 800 \\
MUST12 & $34 \pm 12$ & $31 \pm 1$ & $58.7 \pm 1$ & $1469 \pm 27$ & $2.58 \pm 0.05$ & $2.06 \pm 0.03$ & 1000 \\
MUZTAGH-2 & $48 \pm 12$ & $34 \pm 1$ & $77.9 \pm 1.2$ & $931 \pm 21$ & $2.68 \pm 0.06$ & $1.89 \pm 0.03$ & 400 \\
MUZTAGH-2-1 & $27 \pm 8$ & $32 \pm 0.7$ & $97.5 \pm 1.1$ & $1230 \pm 22$ & $3.00 \pm 0.05$ & $2.34 \pm 0.03$ & 600 \\
MUZTAGH-3 & $65 \pm 11$ & $112.8 \pm 1.4$ & $109.7 \pm 1.3$ & $750 \pm 17$ & $2.99 \pm 0.07$ & $2.66 \pm 0.09$ & 400 \\
MUZTAGH-3-1 & $45 \pm 9$ & $49 \pm 0.8$ & $91.9 \pm 1.2$ & $1061 \pm 21$ & $2.79 \pm 0.05$ & $2.26 \pm 0.05$ & 600 \\
XJ64 & $52 \pm 9$ & $66 \pm 1$ & $91.5 \pm 1.2$ & $1229 \pm 24$ & $2.51 \pm 0.04$ & $2.51 \pm 0.06$ & 1000 \\
XJ64-1 & $24 \pm 7$ & $19.5 \pm 0.6$ & $23.2 \pm 0.7$ & $366 \pm 10$ & $1.19 \pm 0.04$ & $0.70 \pm 0.02$ & 150 \\
\hline
\end{tabular}

786

787

788

789

790

791

792

793

794

795

796

797

798

799

800

801

802

803

804

805

806

807

808

809

810

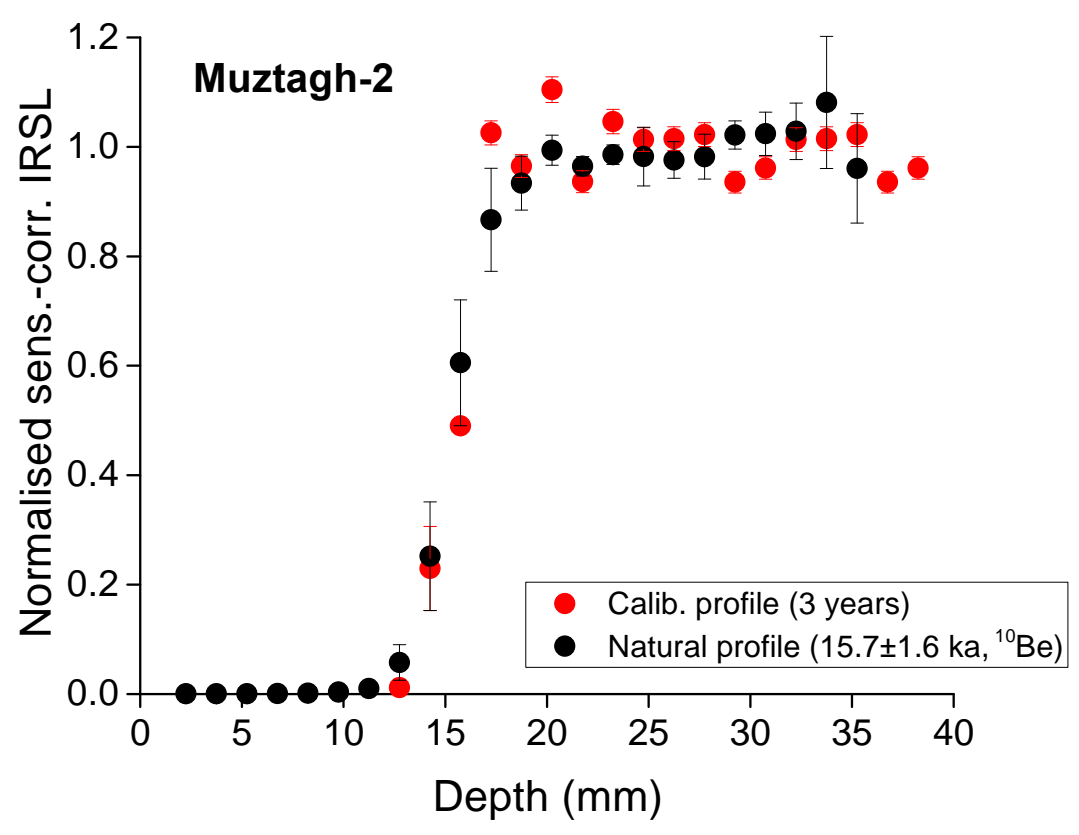

Fig. S1) The 3-year old calibration profile (profile 1, Fig. 4c) superimposed on the natural profile (profile 2, Fig. 4c) by adding $12 \mathrm{~mm}$ to the depths of profile 1. The two profiles are indistinguishable, confirming that any effect of signal instability on the shape of the profile is negligible over a timescale of up to $\sim 16 \mathrm{ka}$.

Table S1) Summary of radionuclide concentrations, infinite matrix beta and gamma dose rates and K-feldspar grain sizes as used in the calculation of total effective dose rate.

(1)




\section{Sensitivity of the fitted value of $\mu$ to erosion rate $(\varepsilon)$ and exposure time $(t)$ ?}

812 In order to investigate the possible effect of erosion on $\mu$, we numerically simulated profiles, using

813 Eqns. (1), (2), (3) and (5), for a range of erosion rates from 0 to $5 \mathrm{~mm} \mathrm{ka}^{-1}$ over a wide range of 814 exposure times from $1 \mathrm{a}$ to $100 \mathrm{ka}$. We then fitted the resulting modelled profiles with Eqn. (4) to 815 determine the best-fit value for $\mu$ (Fig. S2). The variation in the resulting value of $\mu$ obtained using the 816 age model (i.e. no erosion) when fitted to these simulated profiles affected by erosion is $<0.5 \%$ around 817 the true value over an exposure time of up to $100 \mathrm{ka}$.

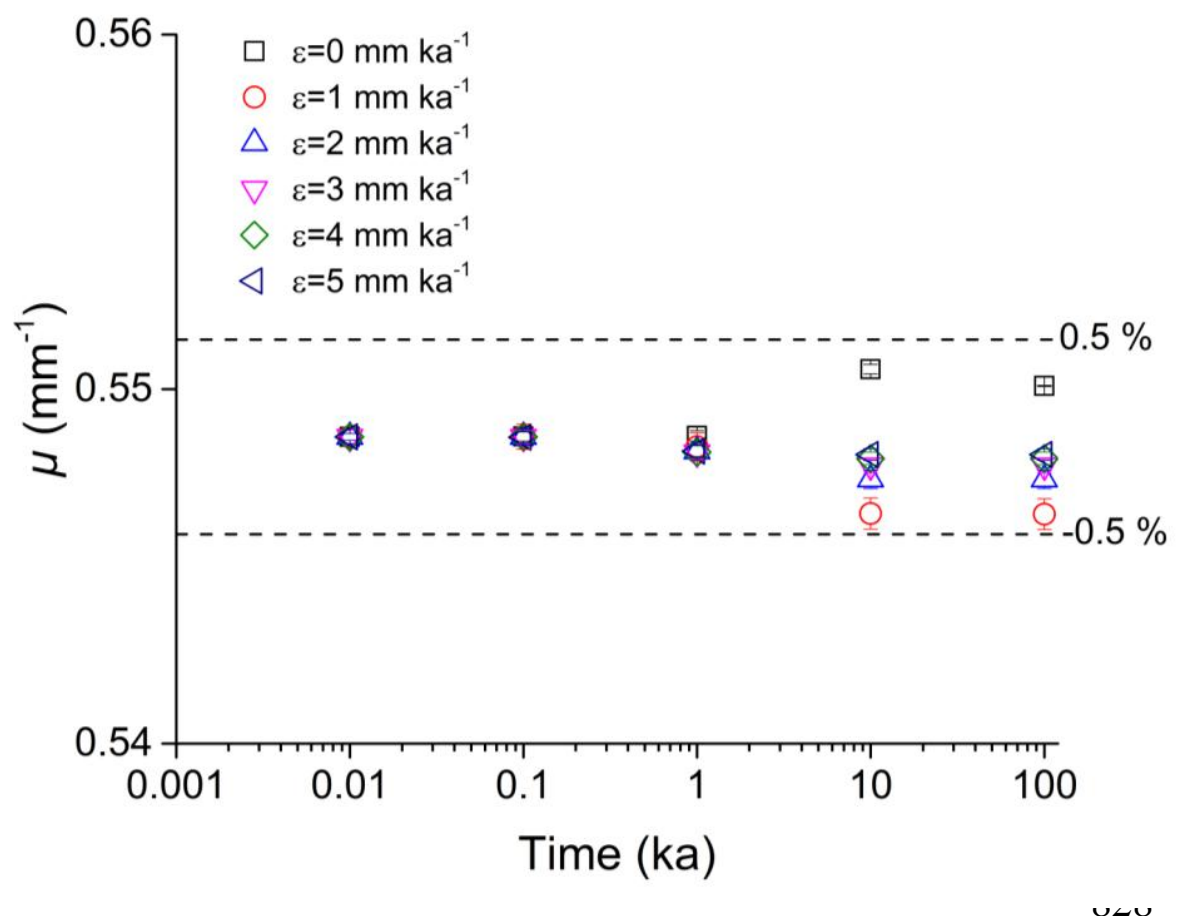

829 Fig. S2) Dependence of fitted $\mu$ on apparent age and erosion rate using numerically simulated data. 